\title{
Lattice Order Group Decision Making with Interval Probability Based on Prospect Theory
}

\author{
Chun-xiang Guo • Ying Peng
}

(C) The Author(s) 2014. This article is published with open access at Springerlink.com

\begin{abstract}
A random lattice order decision analysis method is proposed based on an interval probability distribution preference vector by way of entropy theory, focusing on a decision preference system in which preference relation probability is described by interval values and the decision maker's behavior is also considered. The preference characterization of decision makers is extended from four varieties of relations to seven varieties of preference relations. In addition to the concept, property, and operation rules of interval probability, the concept of interval-valued distribution preference vectors and the relative entropy on the lattice-ordered preference system are given. Then, the interval probability can be more precisely determined, and the weighting interval probability is transformed into the interval probability weight. The ER nonlinear optimization model based on preference entropy is established, individual preferences are aggregated by applying the priority rule and the intersection rule, and the specific steps of decision making are given. Finally, the feasibility and effectiveness of the approach proposed in this paper are illustrated with a numerical example.
\end{abstract}

Keywords Group decision making - Lattice-ordered preference · Interval probability $\cdot$ Preference entropy $\cdot$ Nonlinear optimization

C. Guo (殴)

Business School of Sichuan University, Chengdu 610065, Sichuan, People's Republic of China e-mail: gchx1@sina.com

Y. Peng

Architecture and Environment School of Sichuan University, Chengdu 610065, Sichuan,

People's Republic of China

e-mail: 598803807@qq.com 


\section{Introduction}

Group decision making (GDM) is used to obtain the best solution(s) for a problem according to the information provided by some decision makers. In recent years, how best to solve group ranking problems has become an important issue, and the GDM method has been widely used in many applications, including the selection of advanced manufacturing technology (Chuu 2009), the selection of industrial robotics (Kahraman et al. 2007), and web search strategies. In order to reach a decision, experts must express their opinions or preferences by means of a set of evaluations over a set of options. Usually, each decision maker (expert) may approach the decision process from a different perspective, but they share the common goal of reaching agreement the best decision. Concretely, in a GDM problem, we have a set of options to solve the problem and a set of experts, who are usually required to provide their preferences for the options by means of a particular preference format. At this time, the preference information provided by decision makers can be expressed in multiple formats, such as utility values, multiplicative preference relations, fuzzy preference relations, linguistic variables, interval numbers, and preference rankings or ranking ordinals (Chiclana et al. 2013; Ma 2010; Wang et al. 2005; Guo and Wang 2012; Yager 2011; Angiz et al. 2012; Frini et al. 2012; Lodwick and Jamison 2008; Tavares 2012).

A number of approaches have been developed to solve GDM problems with one or more formats of preference information (Hwang and Lin 1987; Fan et al. 2010; Ma et al. 2006; Xia and Xu 2012; Meng and Pei 2013; Podinovski (2010, 2012)). However, most of the above methods have the drawback of assuming preference information provided by a group of decision makers with total order properties. In fact, each decision maker may express his preferences in different information domains depending on the level of knowledge and experience of decision makers or the nature of options. Studies thus indicate that using ordinal preferences to deal with imprecise, ill-defined, and inarticulate decision-making problems is more appropriate. In addition, the partial preorder preference problems (including indifference, preference, and incomparability relations) have attracted increasing attention from researchers. González-Pachón and Romero (2001) aggregated partial ordinal rankings using an interval goal programming method. Jabeur et al. (2004, 2012), Jabeur and Martel (2007a, b, 2010), studied aggregation procedure, ordinal sorting, weight-determining method, and the decision problem with collective preorder (or reference preorder) preference structure based on the distance measure suggested by Roy and Slowinski (1993) and Jabeur and Martel (2010) also proposed an index to measure the agreement level of an individual preorder with respect to a collective preorder (or reference preorder) and derived binary mathematical programming based on the minimum distance of a collective preorder. Jullien-Ramasso et al. (2012) presented a decision support system for animated films for the International Animated Film Festival organized at Annecy, France, with selection based on the multi-criteria aggregation of referees' ordinal preferences. Lee et al. (2010) proposed collaborative filtering with ordinal scale-based implicit ratings for mobile music recommendations. Cook (2006) and Rebai et al. (2006) also conducted relevant studies.

On the other hand, Saaty (1990) observed that the simplest and most direct methods involve pair-wise comparison of options when decision makers express their prefer- 
ences about options; comparison results are presented using binary preference relations (González-Pachón and Romero 2004; Hüllermeier et al. 2008; Fan et al. 2010; Liu et al. 2014).

In the real world, because of the complexity and uncertainty of decision-making problems, decision results could also be random uncertainty, and thus, it may be difficult for decision makers to express a clear preference relation given that they can only express their uncertain binary preference between options. For example, the decision maker considers that the possibility or probability of $\mathrm{A} 1 \succ \mathrm{A} 2$ is an interval, such as $[0.5,0.7]$.

Many existing approaches have made significant contributions to solve GDM problems with preference rankings or uncertain preference ordinals (González-Pachón and Romero 2011; González-Pachón et al. 2003; Wang et al. 2005). However, the approaches of González-Pachón et al. (2003), González-Pachón and Romero (2001, 2010, 2011), Wang et al. (2005), and Fan et al. (2010) are based on total order or partial order preference, and do not consider lattice-ordered preference or the DM's behavior.

For example, a manufacturer plans to choose green technology for a green product and there are five types of candidate green technology (A1, A2, A3, A4, and A5). The decision maker prefers A1-A2 (denoted as A1 $\succ \mathrm{A} 2$ ); A2 is incomparable to A3, A2 and A3 have an 1.u.b. (denoted as A2 \| A3); A3 is incomparable to A1, A3 and A1 have a g.l.b. (denoted as A3 \| A1); A4 is incomparable to A5, A4 and A5 not only have an 1.u.b., but also a g.l.b. (denoted as A4 $\|_{\wedge}^{\vee}$ A5); A2 is incomparable to A4 (denoted as A2\|A4); and the decision maker is indifferent between A1 and A5 (denoted as $\mathrm{A} 1 \approx \mathrm{A} 5$ ). Here, the decision maker's preference structure has lattice order characteristics.

There are, however, a number of issues.

(i) It should be noted that $\mathrm{A}$ is incomparable to $\mathrm{B}$ (denoted by $A \| B$ ), but most major decision-making problems can gain the least upper bound, the greatest lower bound, or both for alternative pairs by mining some other information between $\mathrm{A}$ and $\mathrm{B}$. Therefore, using only ordinal preference formal information to depict decision makers' preferences is inadequate in many situations.

It is more realistic to describe the preferences of decision makers by using a lattice order structure. For group decision-making problems with lattice order structure, Guo et al. (2003, 2010a, b, 2011, 2012) have furthered research in this area. Guo et al. (2003) expanded the total order of the Von Neumann-Morgenstern rational behavior axiom system to the lattice-ordered sequence, correspondingly weakening the continuity axiom, while maintaining that rational decision-making behavior should be guided by the independence axiom. They thus established the axiom system of lattice-ordered decision-making. Guo et al. (2010a, 2011) proposed a method of group decision making based on the distance of lattice-ordered preferences. Guo et al. (2012) proposed the method of random lattice order group decision making based on interval probability preferences.

(ii) In the uncertain decision process, the binary preference relations between alternative pairs are random, and can be changed based on the binary relations term 
set $\{\succ,\|\|,, \|, \stackrel{\vee}{\vee}, \approx, \prec\}$. Decision makers do not determine the specific status, and it is hard for decision makers to determine the precise probability of the occurrence of binary preference relations given a certain numeral. However, they can determine all possible statuses, and they can quantify this randomness by setting up an interval number probability distribution.

(iii) The DM's behavior is rarely considered. Most existing methods are based on expect utility theory (EUT), and assume that decision makers (DMs) are totally rational. However, because of the ambiguity of problems, individual cognitive limitations, and lack of knowledge, people are not fully rational. Many psychological studies have identified several psychological characteristics of human behavior under risk and uncertainty, including reference dependence, loss aversion, and judgmental distortion of the likelihood of almost impossible and certain outcomes (Schmidt and Zank 2008; Bleichrodt et al. 2009; Abdellaoui et al. 2007; Baucells and Villasís 2010; Cheng et al. 2011). Prospect theory (PT) (Kahneman and Tversky 1979) and Cumulative prospect theory (CPT) (Tversky and Kahneman 1992) reflect the DMs' subjective risk preference. Therefore, it is necessary to consider the DM's psychological behavior in decision analysis in order to provide effective decision support to the DM in actual decision-making situations.

In complex and uncertain environments, in the judgment and decision making process, people might be accustomed to direct and simple thinking, hoping to obtain information about the program's supremum or infimum. Therefore, the purpose of this paper is to provide insight into the combination of DM's random lattice-ordered preference behavior and CPT, using uncertain variables to replace the accurate probability of the binary relation based on the binary relation term set $\{\succ,\|\|,,\|\|,, \approx, \prec\}$.

The rest of this paper is arranged as follows. Section 2 gives a brief introduction to interval probability theory, prospect theory and the description of uncertain preference distribution with interval probability. The ER nonlinear optimization model based on preference entropy and probability weight function is proposed in Sect. 3. Section 4 gives an example to illustrate the feasibility and validity of the proposed method. Section 5 summarizes and highlights the main features of this paper.

\section{Preliminaries}

\subsection{The Interval Probability}

Definition 1 (He 2007) A set of real number intervals $\left[L_{i}, U_{i}\right](i=1,2, \ldots, n)$ with $0 \leq L_{i} \leq U_{i} \leq 1(i=1,2, \ldots, n)$, which can describe the probability of the fundamental event, is called an n-dimensional probability interval (n_PRI). For convenience, the vectors $L=\left(L_{1}, L_{2}, \ldots, L_{n}\right)^{T}$ and $U=\left(U_{1}, U_{2}, \ldots, U_{n}\right)^{T}$ are introduced, and n_PRI is then denoted as n_PRI $(\mathrm{L}, \mathrm{U})$.

Definition 2 (He 2007; Guo and Tanaka 2010) If there exists a group of positive real numbers $p_{1}, p_{2}, \ldots, p_{n}$, where $\sum_{i=1}^{n} p_{i}=1$ and $L_{i} \leq p_{i} \leq U_{i}(i=1,2, \ldots, n)$, n_PRI $(\mathrm{L}, \mathrm{U})$ is reasonable; otherwise, $\mathrm{n} \_\mathrm{PRI}(\mathrm{L}, \mathrm{U})$ is unreasonable. 
Theorem 1 (Yager and Kreinovich 1999)Ann_PRI(L, U) is reasonable iff $\sum_{i=1}^{n} L_{i} \leq$ $1 \leq \sum_{i=1}^{n} U_{i}$. Yager and Kreinovich (1999) proposed that if $n \_P R I(L, U)$ is reasonable, then, the probability intervals $\left[L_{i}, U_{i}\right](i=1,2, \ldots, n)$ can be transformed into more precise probability intervals $\left[\overline{L_{i}}, \overline{U_{i}}\right](i=1,2, \ldots, n)$, where

$$
\overline{L_{i}}=\max \left(L_{i}, 1-\sum_{\substack{j=1 \\ j \neq i}}^{n} U_{j}\right), \overline{U_{i}}=\min \left(U_{i}, 1-\sum_{\substack{j=1 \\ j \neq i}}^{n} L_{j}\right)
$$

\subsection{The Description of Uncertain Preference Distribution with Interval Probability}

The decision problem is now described more formally. Let $D=\left\{D_{1}, \ldots, D_{j}, \ldots, D_{n}\right\}$ be the set of decision makers. When the decision makers want to determine a qualitative preference, the appropriate binary relation set is generally preset. Let $H=\{\succ,\|\|,,\|\|,, \approx, \prec\}$ be a binary relation term set. The decision maker $D_{j}(j=$ $1,2, \ldots, n)$ considers the binary relations between $\mathrm{A}$ and $\mathrm{B}$ to follow some kind of interval-valued probability distribution on $H=\{\succ,\|\|,, \|, \stackrel{\vee}{\|}, \approx, \prec\}$, the corresponding relationship between $\mathrm{A}$ and $\mathrm{B}$ is $r$, and the probability of $\mathrm{A} r \mathrm{~B}$ shown as follows, $\mathrm{q}_{\mathrm{r}}^{\mathrm{j}}=\left[\mathrm{q}_{* \mathrm{r}}^{\mathrm{j}}, \mathrm{q}_{\mathrm{r}}^{* \mathrm{j}}\right]$, is denoted as $\mathrm{Q}=\left\{\mathrm{q}_{r}^{j} \mid \mathrm{q}_{r}^{j}=\left[\mathrm{q}_{* r}^{j}, \mathrm{q}_{r}^{* j}\right]\right\}$, where $\forall r \in H, \mathrm{q}_{* r}^{j} \leq \mathrm{q}_{r}^{* j}$.

Definition 3 Let $H=\{\succ,\|, \stackrel{\vee}{\|}\|,, \stackrel{\vee}{\|}, \approx, \prec\}$ be the set of possible binary relations between $\mathrm{A}$ and $\mathrm{B}$, that is, a state space $\Omega$. If $\forall r \in H$ is the event of the state space, the probability of event $r$ is an interval value $\mathrm{q}_{\mathrm{r}}^{\mathrm{j}}=\left[\mathrm{q}_{* \mathrm{r}}^{\mathrm{j}}, \mathrm{q}_{\mathrm{r}}^{* \mathrm{j}}\right]$, and arbitrary $\mathrm{q}_{\mathrm{r}}^{\mathrm{j}} \in\left[\mathrm{q}_{* \mathrm{r}}^{\mathrm{j}}, \mathrm{q}_{\mathrm{r}}^{* \mathrm{j}}\right]$, if there exist values

$$
\begin{aligned}
& \mathrm{q}_{\succ}^{\mathrm{j}}=\left[\mathrm{q}_{* \succ}^{\mathrm{j}}, \mathrm{q}_{\succ}^{* \mathrm{j}}\right], \quad \mathrm{q}_{\|}^{\mathrm{j}}=\left[\mathrm{q}_{* \|}^{\mathrm{j}}, \mathrm{q}_{\|}^{* \mathrm{j}}\right], \quad \underset{\|}{\mathrm{q}_{v}^{\mathrm{j}}}=\left[\underset{* \|}{\mathrm{q}_{v}^{\mathrm{j}}, \mathrm{q}_{\|}^{* j}}\right], \quad \mathrm{q}_{\|}^{\mathrm{j}}=\left[\underset{\wedge}{\mathrm{q}_{* \|}^{\mathrm{j}}, \mathrm{q}_{\|}^{* j}}\right],
\end{aligned}
$$

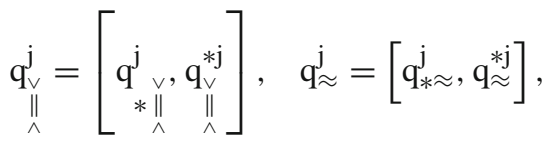

$$
\begin{aligned}
& \mathrm{q}_{\prec}^{\mathrm{j}}=\left[\mathrm{q}_{* \prec}^{\mathrm{j}}, \mathrm{q}_{\prec}^{* \mathrm{j}}\right] \text { for which } \\
& 0 \leq \mathrm{q}_{* \mathrm{r}}^{\mathrm{j}} \leq \mathrm{q}_{\mathrm{r}}^{* \mathrm{j}} \leq 1, \quad \sum_{r \in\{\succ,\|,\|,\|,\|, \|, \approx,<\}} \mathrm{q}_{r}^{\mathrm{j}}=1 .
\end{aligned}
$$


We say that the sequence of interval probabilities $\mathrm{q}_{\mathrm{r}}^{\mathrm{j}}=\left[\mathrm{q}_{* \mathrm{r}}^{\mathrm{j}}, \mathrm{q}_{\mathrm{r}}^{* \mathrm{j}}\right]$ is consistent, or, to be more accurate, forms an interval probability distribution based on $H=$ $\{\succ,\|\|,, \|, \stackrel{\vee}{\|}, \approx, \prec\}$.

It can be seen from Definition 1 that the point-valued probability mass function is extended into the interval-valued function. The following theorem is used to judge whether the given intervals qualify as interval probabilities.

Theorem 2 The set of intervals $Q=\left\{q_{r}^{j} \mid q_{r}^{j}=\left[q_{* r}^{j}, q_{r}^{* j}\right]\right\}\left(\forall r \in H, q_{* r}^{j} \leq q_{r}^{* j}, H=\right.$ $\left.\left\{\succ,\|\|,,\|,\| \|_{\wedge}^{\vee} \approx, \prec\right\}\right)$ satisfies (2) if and only if the following conditions hold.

$$
\begin{aligned}
& \left\{\begin{array}{l}
q_{\succ}^{* \mathrm{j}}+q_{* \|}^{\mathrm{j}}+q_{* \mho}^{\mathrm{j}}+\cdots+q_{* \approx}^{\mathrm{j}}+q_{* \prec}^{\mathrm{j}} \leq 1 \\
q_{\|}^{* \mathrm{j}}+q_{* \succ}^{\mathrm{j}}+q_{* \mho}^{\mathrm{j}}+\cdots+q_{* \approx}^{\mathrm{j}}+q_{* \prec}^{\mathrm{j}} \leq 1 \\
\vdots \\
q_{\prec}^{* \mathrm{j}}+q_{* \succ}^{\mathrm{j}}+q_{* \|}^{\mathrm{j}}+q_{* \|}^{\mathrm{j}}+\cdots+q_{* \approx}^{\mathrm{j}} \leq 1
\end{array}\right. \\
& \left\{\begin{array}{l}
q_{* \succ}^{\mathrm{j}}+q_{\|}^{* \mathrm{j}}+q_{\searrow}^{* \mathrm{j}}+\cdots+q_{\|}^{* \mathrm{j}}+q_{\prec}^{* \mathrm{j}} \geq 1 \\
q_{* \|}^{\mathrm{j}}+q_{\succ}^{* \mathrm{j}}+q_{\Perp}^{* \mathrm{j}}+\cdots+q_{\|}^{* \mathrm{j}}+q_{\prec}^{* \mathrm{j}} \geq 1 \\
\vdots \\
q_{* \prec}^{\mathrm{j}}+q_{\succ}^{* \mathrm{j}}+q_{\|}^{* \mathrm{j}}+q_{\|}^{* \mathrm{j}}+\cdots+q_{\wedge}^{* \mathrm{j}} \geq 1
\end{array}\right.
\end{aligned}
$$

It should be noted that the proof of Theorem 2 is based on Theorem 2.2 of Weichselberger and Pohlmann (1990). It is clear that if there are only two binary relations, that is, $H=\{\succ, \prec\}$, then $\mathrm{q}_{* \succ}^{\mathrm{j}}+\mathrm{q}_{\prec}^{* \mathrm{j}}=1, \mathrm{q}_{\succ}^{* \mathrm{j}}+\mathrm{q}_{* \prec}^{\mathrm{j}}=1$ hold, and if we have no knowledge of $R$, we can express this complete ignorance as $\mathrm{q}_{* r}^{\mathrm{j}}+\mathrm{q}_{r}^{* \mathrm{j}}=[0,1]$, which satisfies (3) and (4), indicating that the decision environment is uncertain.

Let us consider a more general case where a set of intervals $Q^{\prime}=\left\{\mathrm{q}_{r}^{\prime} \mid \mathrm{q}_{\mathrm{r}}^{\prime}=\left[\mathrm{q}_{\mathrm{lr}}, \mathrm{q}_{\mathrm{ur}}\right]\right\}$ corresponding to a finite event set $\mathrm{H}=\{\succ,\|\|,,\|,\| \wedge, \approx, \prec\}(\forall r \in \mathrm{R})$ satisfies the following inequalities:

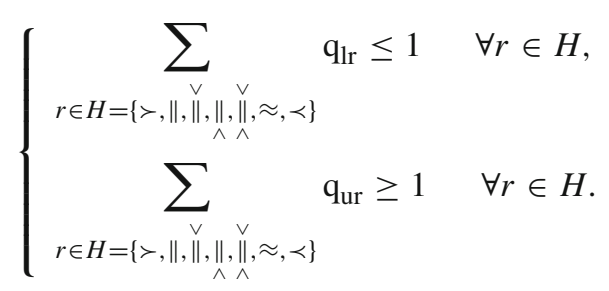

It is clear that (5) and (6) are necessary conditions of (3) and (4), respectively. In other words, (3) and (4) are relaxed as (5) and (6), respectively. 
Definition 4 Let a set of intervals $\left.\mathrm{Q}=\mathrm{q}_{r}^{j} \mid \mathrm{q}_{r}^{j}=\left[\mathrm{q}_{* r}^{j}, \mathrm{q}_{r}^{* j}\right]\right\}$ be an interval-valued probability of a finite event set $H=\left\{\succ,\|\|,\left\|_{\wedge}^{\vee}\right\|, \underset{\wedge}{\vee}, \approx, \prec\right\}\left(\forall r \in H, \mathrm{q}_{* r}^{j} \leq \mathrm{q}_{r}^{* j}\right)$. In terms of the preference of the expert $e_{j}$, because the finite set $H$ of the event that is independent, $\forall \mathrm{q}_{r}^{j}=\left[\mathrm{q}_{* r}^{j}, \mathrm{q}_{r}^{* j}\right], \tilde{\mathrm{q}}_{r}^{j}=\left[\tilde{\mathrm{q}}_{* r}^{j}, \tilde{\mathrm{q}}_{r}^{* j}\right], 1 \geq k \geq 0$, and thus,

(1) $\mathrm{q}_{r}^{j}+\tilde{\mathrm{q}}_{r}^{j}=\left[\mathrm{q}_{* r}^{j}+\tilde{\mathrm{q}}_{* r}^{j}, \mathrm{q}_{r}^{* j}+\tilde{\mathrm{q}}_{r}^{* j}\right]$;

(2) $\mathbf{q}_{r}^{j} \times \tilde{\mathrm{q}}_{r}^{j}=\left[\min \left(\mathrm{q}_{* r}^{j} \cdot \tilde{\mathrm{q}}_{* r}^{j}, \mathrm{q}_{* r}^{j} \cdot \tilde{\mathrm{q}}_{r}^{* j}, \mathrm{q}_{r}^{* j} \cdot \tilde{\mathrm{q}}_{* r}^{j}, \mathrm{q}_{r}^{* j} \cdot \tilde{\mathrm{q}}_{r}^{* j}\right), \max \left(\mathbf{q}_{* r}^{j} \cdot \tilde{\mathrm{q}}_{* r}^{j}, \mathrm{q}_{* r}^{j} \cdot \tilde{\mathrm{q}}_{r}^{* j}, \mathrm{q}_{r}^{* j}\right.\right.$. $\left.\left.\tilde{\mathrm{q}}_{* r}^{j}, \mathrm{q}_{r}^{* j} \cdot \tilde{\mathrm{q}}_{r}^{* j}\right)\right]$;

(3) $\mathrm{k} \mathrm{q}_{r}^{j}=\left[\mathrm{k} \mathrm{q}_{* r}^{j}, \mathrm{k} \mathrm{q}_{r}^{* j}\right]$ hold.

\subsection{Prospect Theory}

The prospect theory (PT) of Kahneman and Tversky (1979), Tversky and Kahneman (1992) is an alternative theory of decision making under uncertainty to the standard Morgenstern-von Neumann utility theory. Based on a series of experimental observations, Kahneman and Tversky proposed a value function defined by the gains or losses relative to a reference point instead of the absolute level of consumption or wealth.

Specifically, they state that the value function formed with subjective feelings of the decision maker in prospect theory is $\mathrm{v}(\mathrm{x})$. The value function given by Tversky and Kahneman has the form of a power function:

$$
v(x)=\left\{\begin{array}{ll}
x^{\alpha}, & x \geq 0 \\
-\theta(-x)^{\beta}, & x<0
\end{array},\right.
$$

where $\alpha$ and $\beta$ denote, respectively, the bump degree of the value power function in the gain and loss regions and $0<\alpha, \beta<1$ denotes diminishing sensitivity. $\theta$ is used to indicate that the loss region is steeper than the gain region.

In PT (Tversky and Kahneman 1992), prospect value v(x) depends not only on value function $v$ but also on the inverse $S$-shaped weighting function. Kahneman and Tversky (1979), Tversky and Kahneman (1992) considered the probability weight to be the subjective judgment of the decision maker based on the probability p of the event outcome, and it is neither the probability nor the linear function of the probability. It is the corresponding weight on the probability. The probability weight function is as follows:

$$
\begin{aligned}
w^{+}(p) & =\frac{p^{\gamma}}{\left(p^{\gamma}+(1-p)^{\gamma}\right)^{1 / \gamma}}, \\
w^{-}(p) & =\frac{p^{\delta}}{\left(p^{\delta}+(1-p)^{\delta}\right)^{1 / \delta}},
\end{aligned}
$$

where $w^{+p}$ and $w^{-p}$ are the nonlinear weight functions of the gains and losses, respectively, $\gamma>0$ is the risk gain attitude coefficient, and $\delta$ is the risk loss attitude coefficient. Kahneman and Tversky (1979), Tversky and Kahneman (1992) considered $\gamma=0.6, \delta=0.72$; Richard and Wu (1999) considered $\gamma=0.74, \delta=0.74$. 
The characteristics of the probability weight function are as follows:

(i) The response to the change of the probability is nonlinear.

(ii) The probability weight function is not the probability and $w(p)$ is the increasing function of the probability $\mathrm{p}$, but it does not obey the probability axioms and it should not be interpreted as the extent of the individual's expectation.

(iii) When the value of the probability $\mathrm{p}$ is small, then $\mathrm{w}(\mathrm{p})>\mathrm{p}$, which shows that the decision makers overvalued the small probability event; however, when the value of the probability $\mathrm{p}$ is large, then $\mathrm{w}(\mathrm{p})<\mathrm{p}$, which shows that the decision makers ignore the normal event.

\section{The Decision-Making Method}

\subsection{The Description of the Interval-Valued Distribution Preference Vector}

Let $D=\left\{D_{1}, \ldots, D_{i}, \ldots, D_{m}\right\}$ be the set of $m$ decision makers. The relative weights of $\mathrm{m}$ decision makers are denoted by $w=\left(w_{1}, \ldots, w_{i} \ldots, w_{m}\right), w_{i}=\left[\underline{w}_{i}, \bar{w}_{i}\right]$, which are known or given and satisfy the following condition: $\sum_{i=1}^{m} w_{i}=1,1 \geq w_{i} \geq$ 0 . Let $H=\left\{r_{j} \mid j=1, \ldots, 7\right\}=\left\{\succ,\|, \stackrel{\vee}{\|},\|{ }_{\wedge}^{\vee}, \approx, \prec\right\}$ be the possible binary relations between $\mathrm{A}$ and $\mathrm{B}$, which are mutually exclusive and collectively exhaustive. The seven binary relations form the frame of discernment $H=\left\{r_{1}, r_{2}, \ldots, r_{7}\right\}$ in the probability theory, and the preference of decision maker $D_{i}$ is an event. If the relation of alternative pair (A, B) is $r_{j} \in\{\succ,\|\|,, \|, \underset{\wedge}{\|}, \approx, \prec\}$ with an interval probability $q_{i}\left(r_{j}\right)=$ $\left[q_{i}^{-}\left(r_{j}\right), q_{i}^{+}\left(\left(r_{j}\right)\right]\left(r_{j} \in H\right)\right.$, we denote this by $S\left(D_{i}(A, B)=\left\{r_{j},\left[q_{i}^{-}\left(r_{j}\right), q_{i}^{+}\left(r_{j}\right)\right]\right\}\right.$, which is an interval-valued distribution preference vector, where $q_{i}^{-}\left(r_{j}\right) \geq 0$. Note that precise probability is a special case of interval probability with $q_{i}^{-}\left(r_{j}\right)=q_{i}^{+}\left(r_{j}\right)$, and the decision preference system is denoted by $S=(\mathrm{H}, \mathrm{D})$.

Definition 5 Let $S\left(D_{i}(A, B)=\left\{r_{j},\left[q_{i}^{-}\left(r_{j}\right), q_{i}^{+}\left(r_{j}\right)\right], r_{j} \in\{\succ,\|\|,,\|\|,, \stackrel{\vee}{\|}, \approx, \prec\}\right\}\right.$ be an interval-valued distribution preference vector of the preference system $S=(\mathrm{H}, \mathrm{D})$. If the interval probability $\left[q_{i}^{-}\left(r_{j}\right), q_{i}^{+}\left(r_{j}\right)\right]$ satisfies $\sum_{r_{j} \in\{\succ,\|,\|,\|,\|, \approx, \prec\}} q_{i}^{-}\left(r_{j}\right) \leq 1$, then $S\left(D_{j}(A, B)\right.$ is said to be valid; otherwise, it is invalid.

An invalid interval-valued distribution assessment vector must be revised or adjusted before it can be used to conduct decision analysis.

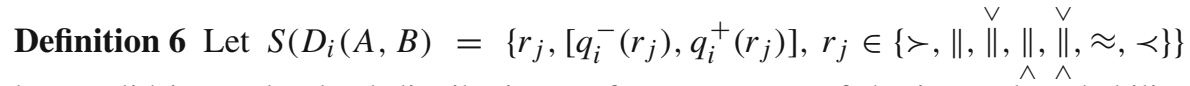
be a valid interval-valued distribution preference vector. If the interval probability $q_{i}\left(r_{j}\right)=\left[q_{i}^{-}\left(r_{j}\right), q_{i}^{+}\left(r_{j}\right)\right]\left(q_{j}^{-}\left(r_{j}\right) \leq q_{j}^{+}\left(r_{j}\right)\right.$ of $D_{i}$ satisfies $\sum_{r_{j} \in\{\succ,\|,\|,\|,\|, \|, \approx,<\}} q_{i}\left(r_{j}\right)$ $=1$ in all circumstances, where $q_{i}\left(r_{j}\right) \in\left[q_{i}^{-}\left(r_{j}\right), q_{i}^{+}\left(r_{j}\right)\right]$ for each $r_{j} \in$ $\{\succ,\|\|,,\|,\| \wedge, \approx, \prec\}$, then $S\left(D_{i}(A, B)\right.$ is said to be a complete interval-valued 
distribution preference vector; otherwise, it is incomplete. In particular, when $\sum_{r \in\{\succ,\|,\|, \|, \cup \wedge, \approx,<\}} q_{j}^{+}(r)=0$, the preference is said to be totally ignorant.

For a complete interval-valued distribution preference vector, the preference relations between $A, B$ are certain to be one or more of the defined binary relations, and there is no remaining probability assigned to the whole set $\mathrm{H}$. However, if an intervalvalued distribution preference vector is incomplete, then there might be an interval probability that is unassigned to any of the defined binary relations. This unassigned interval probability should be assigned to the whole set $\mathrm{H}$.

\subsection{Decision with Interval Probabilities}

In this section, we discuss how to make a decision with the estimated interval probabilities.

(1) The interval-valued distribution preference vector is transformed into the weighting preference vector.

Let $S\left(D_{i}(A, B)=\left\{r_{j},\left[q_{i}^{-}\left(r_{j}\right), q_{i}^{+}\left(r_{j}\right)\right], r_{j} \in\{\succ,\|, \stackrel{\vee}{\|}\|,, \underset{\wedge}{\|}, \approx, \prec\}\right\}\right.$ be a valid interval-valued distribution preference vector of $D_{i}$.

A. Make the interval probability more precise.

Based on formula (1), we can get a more precise interval probability as follows:

$$
\begin{aligned}
& \tilde{q}_{i}(\succ)=\left[\tilde{q}_{i}^{-}(\succ), \tilde{q}_{i}^{+}(\succ)\right], \quad \tilde{q}_{i}(\|)=\left[\tilde{q}_{i}^{-}(\|), \tilde{q}_{i}^{+}(\|)\right], \ldots, \\
& \tilde{q}_{i}(\prec)=\left[\tilde{q}_{i}^{-}(\prec), \tilde{q}_{i}^{+}(\prec)\right],
\end{aligned}
$$

where $0 \leq \tilde{q}_{i}^{-}\left(r_{j}\right) \leq \tilde{q}_{i}^{+}\left(r_{j}\right) \leq 1$, but $\sum_{j=1}^{n} \tilde{q}_{i}^{-}\left(r_{j}\right) \leq 1$ and $\sum_{j=1}^{n} \tilde{q}_{i}^{+}\left(r_{j}\right) \geq$ 1 do not have to be satisfied.

It is easy to check that $\tilde{q}_{i}^{-}\left(r_{j}\right) \geq 1-\sum_{l \neq \mathrm{j}} \tilde{\mathrm{q}}_{\mathrm{i}}^{+}\left(r_{l}\right), \tilde{q}_{i}^{+}\left(r_{j}\right) \leq 1-\sum_{l \neq \mathrm{j}} \tilde{\mathrm{q}}_{\mathrm{i}}^{-}\left(r_{l}\right)$ for all $r_{j}$.

B. The referenced priority weight of decision maker $D_{i}$ is denoted by $w_{i}=$ $\left[\underline{w}_{i}, \bar{w}_{i}\right]$. By interval arithmetic (Definition 4), $\bar{m}_{i}\left(r_{j}\right)=\left[\bar{m}_{i}^{-}(\succ), \bar{m}_{i}^{+}(\succ)\right]$ can be obtained, where

$$
\bar{m}_{i}\left(r_{j}\right)=w_{i} \tilde{q}_{i}\left(r_{j}\right) \in\left[w_{i} \tilde{q}_{i}^{-}\left(r_{j}\right), w_{i} \tilde{q}_{i}^{+}\left(r_{j}\right)\right]
$$

$0 \leq \bar{m}_{i}^{-}\left(r_{j}\right) \leq \bar{m}_{i}^{+}\left(\left(r_{j}\right) \leq 1, \quad \sum_{i=1}^{n} w_{i}=1, \quad\right.$ and $1 \geq w_{i} \geq 0$. In addition, let

$$
\bar{m}_{i}(H)=1-\sum_{r_{j} \in\left\{\succ,\|,\|,\|,\|_{\wedge}, \underset{\wedge}{\vee} \approx, \prec\right\}} \bar{m}_{i}\left(r_{j}\right) \in\left[\bar{m}_{i}^{-}(H), \bar{m}_{i}^{+}((H)],\right.
$$


where $\overline{\mathrm{m}}_{\mathrm{i}}^{-}(\mathrm{H})=\max \left(0,1-\sum_{\mathrm{r}_{\mathrm{j}} \in\{\succ,\|,\|,\|,\|, \|, \approx,<\}} \overline{\mathrm{m}}_{\mathrm{i}}^{+}\left(\mathrm{r}_{\mathrm{j}}\right)\right), \overline{\mathrm{m}}_{\mathrm{i}}^{+}(\mathrm{H})=\min (1,1-$

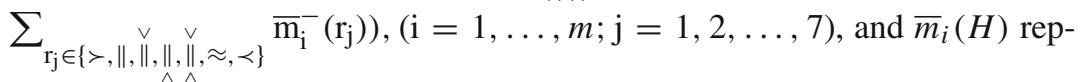
resent the probability of binary relation uncertainty between $\mathrm{A}$ and $\mathrm{B}$ about decision maker $D_{i}$.

Using (9) and (10), we can obtain the weighting preference vector, denoted by

$$
\tilde{S}\left(D_{i}(A, B)\right)=\left\{r_{j},\left[\bar{m}_{i}^{-}\left(r_{j}\right), \bar{m}_{i}^{+}\left(r_{j}\right)\right], r_{j} \in\{\succ,\|,\|, \|, \underset{\wedge}{\vee}, \underset{\wedge}{\vee} \approx, \prec\}\right\}
$$

(2) The weighting interval probability is transformed into the interval probability weight. Based on the formulas (7) and (8), the interval probability weights of $\bar{m}_{i}\left(r_{j}\right)=\left[\bar{m}_{i}^{-}\left(r_{j}\right), \bar{m}_{i}^{+}\left(\left(r_{j}\right)\right]\right.$ are denoted by

$$
m_{i}\left(r_{j}\right)=\left[m_{i}^{-}\left(r_{j}\right), m_{i}^{+}\left(\left(r_{j}\right)\right]=\left[w\left(\bar{m}_{i}^{-}\left(r_{j}\right)\right), w\left(\bar{m}_{i}^{+}\left(r_{j}\right)\right)\right]\left(r_{j} \in H\right) .\right.
$$

When $m_{i}^{+}\left(\left(r_{j}\right)\right.$ and $m_{i}^{-}\left(r_{j}\right)$ are the nonlinear weight functions of the gains,

$$
\begin{aligned}
m_{i}^{+}\left(r_{j}\right) & =\frac{\left[\bar{m}_{i}^{+}\left(r_{j}\right)\right]^{\gamma}}{\left[\bar{m}_{i}^{+}\left(r_{j}\right)+\left(1-\bar{m}_{i}^{+}\left(r_{j}\right)\right)^{\gamma}\right]^{1 / \gamma}}, \\
m_{i}^{-}\left(r_{j}\right) & =\frac{\left[\bar{m}_{i}^{-}\left(r_{j}\right)\right]^{\gamma}}{\left[\bar{m}_{i}^{-}\left(r_{j}\right)+\left(1-\bar{m}_{i}^{-}\left(r_{j}\right)\right)^{\gamma}\right]^{1 / \gamma}},
\end{aligned}
$$

When $m_{i}^{+}\left(r_{j}\right)$ and $m_{i}^{-}\left(r_{j}\right)$ are the nonlinear weight function of the losses,

$$
\begin{aligned}
m_{i}^{+}\left(r_{j}\right) & =\frac{\left[\bar{m}_{i}^{+}\left(r_{j}\right)\right]^{\delta}}{\left[\bar{m}_{i}^{+}\left(r_{j}\right)+\left(1-\bar{m}_{i}^{+}\left(r_{j}\right)\right)^{\gamma}\right]^{1 / \delta}}, \\
m_{i}^{-}\left(r_{j}\right) & =\frac{\left[\bar{m}_{i}^{-}\left(r_{j}\right)\right]^{\delta}}{\left[\bar{m}_{i}^{-}\left(r_{j}\right)+\left(1-\bar{m}_{i}^{-}\left(r_{j}\right)\right)^{\gamma}\right]^{1 / \delta}} .
\end{aligned}
$$

Here, $\gamma>0$ is the risk gain attitude coefficient and $\delta$ is the risk loss attitude coefficient.

(3) Decision-making model

Definition 7 Let $S=(\mathrm{H}, \mathrm{D})$ be the decision preference system. Then, the intervalvalued distribution preference vector of $D_{i}$ is $S\left(D_{i}(A, B)=\left\{r_{j},\left[q_{i}^{-}\left(r_{j}\right), q_{i}^{+}\left(r_{j}\right)\right], r_{j}\right.\right.$ $\in\{\succ,\|\|,,\|,\| \vee \|, \approx, \prec\}\}$, where $q_{i}^{-}\left(r_{j}\right) \leq q_{i}^{+}\left(r_{j}\right)$. By steps (1)-(2), we can obtain the interval probability weights $m_{i}\left(r_{j}\right)=\left[m_{i}^{-}\left(r_{j}\right), m_{i}^{+}\left(\left(r_{j}\right)\right]\left(r_{j} \in H\right)\right.$.

Denote the entropy of system $S$ by $H(S)$; then, $H(S)=-\sum_{r_{j} \in\{\succ,\|, \stackrel{\sim}{\vee},\|, \stackrel{\vee}{\wedge}, \approx,<\}}$ $m_{i}\left(r_{j}\right) \ln m_{i}\left(r_{j}\right)$, where $m_{i}\left(r_{j}\right)$ is the interval probability weight of binary relation 
$r_{j}$ and $H(S)$ is the preference entropy of the system $S . H(S)$ reflects the granularity size of the decision classification and embodies the decision classification of the influence of uncertainty, the fine decision classification; that is, the smaller the particle size, the greater the uncertainty of decision making.

Cross entropy is used to measure the discrimination information according to Shannon's inequality. We give a definition of interval-valued distribution preference vector cross entropy.

Definition 8 Let $S=(\mathrm{H}, \mathrm{D})$ be the decision preference system, $H=\left\{r_{j} \mid j=\right.$ $1, \ldots, 7\}=\{\succ,\|, \stackrel{\vee}{\|}\|,, \|, \approx, \prec\}$ the frame of discernment, and $D_{i}, D_{k} \notin D$, the interval probability weight support $r_{j}$ of $D_{i}$ and $D_{k}$ denoted as $m_{i}\left(r_{j}\right)=\left[m_{i}^{-}\left(r_{j}\right), m_{i}^{+}\left(r_{j}\right)\right]$ and $m_{k}\left(r_{j}\right)=\left[m_{k}^{-}\left(r_{j}\right), m_{k}^{+}\left(r_{j}\right)\right]$.

The relative entropy or Kullback-Leibler information measure between the two preference distributions $D_{i}$ and $D_{k}$ is defined as $H\left(D_{i}, D_{k}\right)=\sum_{r_{j} \in\{\succ,\|,\|, \|, \stackrel{\vee}{\wedge}, \approx, \prec\}}$ $m_{i}(r) \ln \frac{m_{i}\left(r_{j}\right)}{m_{k}\left(r_{j}\right)} \geq 0$.

The above measures describe the cross entropy for interval-valued distribution preference vectors. Obviously, the relative entropy between $D_{i}$ and $D_{k}$ satisfy the following properties:

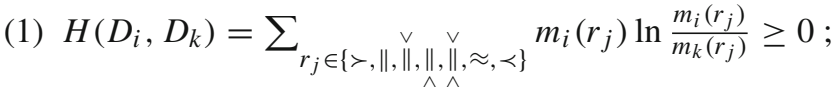

(2) $H\left(D_{i}, D_{k}\right)=\sum_{r_{j} \in\{\succ,\|,\|,\|,\|, \sim, \sim\}} m_{i}\left(r_{j}\right) \ln \frac{m_{i}\left(r_{j}\right)}{m_{k}\left(r_{j}\right)}=0$ if and only if $m_{i}\left(r_{j}\right)=$ $m_{k}\left(r_{j}\right) \quad \forall j$.

According to the above properties, the cross entropy, which can be described as the measure of divergence between $D_{i}$ and $D_{k}$, is $H\left(D_{i}, D_{k}\right)=0$ when the intervalvalued distribution preference of $D_{i}$ and $D_{k}$ are the same.

Therefore, the cross entropy is a measure of the distance between two preference distributions. We use cross entropy to measure the preference consistency of decision makers. When the entropy value is zero, the group has achieved a complete consensus, with no disagreement. When the entropy value is one, there is no consensus, and individuals have large differences of opinion. That is, when the entropy value is smaller, group opinion is more unified. According to the properties of relative entropy, therefore, we have the following optimization problem:

$$
\min \sum_{i=1}^{n} H\left(D, D_{i}\right)=\min \sum_{i=1}^{n} \sum_{\substack{\vee \\ \mathrm{r}_{\mathrm{j}} \in\{\succ,\|,\|,\|,\| \wedge, \approx,<\}}} \mathrm{m}_{\mathrm{i}}\left(\mathrm{r}_{\mathrm{j}}\right) \ln \frac{\mathrm{m}_{\mathrm{i}}\left(\mathrm{r}_{\mathrm{j}}\right)}{\mathrm{m}\left(\mathrm{r}_{\mathrm{j}}\right)},
$$




$$
\begin{aligned}
& \text { s.t. } \quad m^{-}\left(r_{j}\right) \leq m\left(r_{j}\right) \leq m^{+}\left(r_{j}\right), \\
& 0 \leq m^{-}\left(r_{j}\right) \leq m^{+}\left(\left(r_{j}\right) \leq 1,\right. \\
& \sum_{\substack{\vee \\
r_{j} \in\{\succ,\|,\|, \|, \approx, \sim, \prec\}}} m\left(r_{j}\right)=1, \\
& \sum_{i=1}^{n} w_{i}=1 \quad \text { and } 1 \geq w_{i} \geq 0 .
\end{aligned}
$$

Then, the smaller the value of Eq. (17), the smaller is the divergence among the decision group. The constraint conditions of the model (17-18) are linear and bounded, so the feasible solution set not only exists, but also is bounded and concave. In addition, the objective function is continuous and differentiable; the model must have an optimal solution. In addition, the objective function is strictly concave, so there must be a unique solution. The optimization problem can be used directly to solve the calculation with the software Lingo 8.0.

The group distribution preference vector is as follows, from Lingo 8.0:

$$
S\left(D(A, B)=\left\{\left(r_{j}, \mathrm{~m}\left(\mathrm{r}_{\mathrm{j}}\right) ; \mathrm{H}, \mathrm{m}(\mathrm{H})\right)\right\}, r_{j} \in\{\succ, \|, \underset{\wedge}{\vee}, \underset{\wedge}{\|} \underset{\wedge}{\|} \approx, \prec\} .\right.
$$

The group preference probability of $A r_{j} B$ is $m\left(r_{j}\right)$, the group preference probability of $A r_{\mathrm{j}^{\prime}} B$ is $m\left(r_{\mathrm{j}^{\prime}}\right)$, and the binary relation set of the group preference about alternative pair $(A, \mathrm{~B})$ is $\mathrm{R}^{*}(\mathrm{~A}, \mathrm{~B})$, where $\sigma$ is a given parameter. Setting $0<\sigma<1$, we then determine the binary relation between alternative pair $(A, \mathrm{~B})$ via two steps:

(1) If there exist $\mathrm{j}$ and $\forall \mathrm{j}^{\prime} \neq \mathrm{j}$ such that $m\left(r_{j}\right)-\mathrm{m}\left(\mathrm{r}_{\mathrm{j}^{\prime}}\right) \geq \sigma$, then, $r_{j} \in \mathrm{R}^{*}(\mathrm{~A}, \mathrm{~B})$; otherwise, go to the next step.

(2) If $\forall \mathrm{j}^{\prime \prime} \neq \mathrm{j} \neq \mathrm{j}^{\prime}$ such that $m\left(r_{j}\right)-\mathrm{m}\left(\mathrm{r}_{\mathrm{j}^{\prime \prime}}\right) \geq \sigma$ and $m\left(r_{j^{\prime}}\right)-\mathrm{m}\left(\mathrm{r}_{\mathrm{j}^{\prime \prime}}\right) \geq \sigma$, if $\left|m\left(r_{j}\right)-\mathrm{m}\left(\mathrm{r}_{\mathbf{j}^{\prime}}\right)\right|<\sigma$, then $r_{j}, \mathrm{r}_{\mathbf{j}^{\prime}} \in \mathrm{R}^{*}(\mathrm{~A}, \mathrm{~B})$.

\section{A Practical Example}

Process planning is vital in green manufacturing, and the process category selection for green manufacturing is its primary content. In numerous manufacturing processes, there are multiple feasible technology schemes. It is necessary to comprehensively consider the time, quality, cost, resources, environmental effects, and other factors.

There is a green product manufactured with green technology, the green product manufacturing process has been analyzed, there are five process categories from which to choose. Then, let $X=\left\{\mathrm{A}_{1}, \mathrm{~A}_{2}, \ldots, \mathrm{A}_{5}\right\}$ be the process categories. Let $E=\left\{D_{1}, D_{2}, \ldots, D_{5}\right\}$ be a set of five experts (technology chief engineers, quality managers, external experts, etc.); then, the referenced priority weight of expert $D_{i}$ is denoted by $w_{i}=\left[\underline{w}_{i}, \bar{w}_{i}\right], \mathrm{w}_{1}=[0.08,0.086], \mathrm{w}_{2}=[0.05,0.101], \mathrm{w}_{3}=$ $[0.04,0.072], \mathrm{w}_{4}=0.505, \mathrm{w}_{5}=[0.253,0.272]$, and $1 \geq w_{i} \geq 0, \sum_{i-1}^{5} w_{i}=1$.

Considering the influence of different decision-making environments and decision makers' abilities and range of knowledge, decision makers can only give the ordinal 
preferences of the process category. The experts' preferences on process categories are shown in Tables 1, 2, 3, 4 and 5, and are described by interval-valued distribution preference vectors. For example, [0.08, 0.54] in line 2, column 2 of Table 1 is the probability of $\mathrm{A} 1 \succ \mathrm{A} 2$ for expert D1.

Enterprise processing technology is selected as the process category. According to the given conditions in this case and the related knowledge, the selection steps could be summarized as follows:

Step 1: Structure the set of process-kind pairs: $\{(\mathrm{A} 1, \mathrm{~A} 2), \ldots,(\mathrm{A} 1, \mathrm{~A} 5),(\mathrm{A} 2, \mathrm{~A} 3)$, $\ldots,(\mathrm{A} 2, \mathrm{~A} 5), \ldots,(\mathrm{A} 4, \mathrm{~A} 5\}$.

Step 2: Make the interval probability more precise.

Based on the formula (1), $\forall\left(A_{l}, A_{g}\right), A_{l}, A_{g} \in X$, we obtain

$$
\begin{aligned}
\tilde{S}\left(D_{i}\left(A_{l}, A_{g}\right)\right. & =\left\{r_{j},\left[\tilde{q}_{i}^{-}\left(r_{j}\right), \tilde{q}_{i}^{+}\left(r_{j}\right)\right], r_{j} \in\{\succ,\|,\| \underset{\wedge}{\vee \|}, \stackrel{\wedge}{\|}, \approx, \prec\}\right\}, \\
\tilde{q}_{i}(\succ) & =\left[\tilde{q}_{i}^{-}(\succ), \tilde{q}_{i}^{+}(\succ)\right], \tilde{q}_{i}(\|)=\left[\tilde{q}_{i}^{-}(\|), \tilde{q}_{i}^{+}(\|)\right], \ldots, \tilde{q}_{i}(\prec) \\
& =\left[\tilde{q}_{i}^{-}(\prec), \tilde{q}_{i}^{+}(\prec)\right] .
\end{aligned}
$$

The more precise interval probability is shown in Tables 6, 7, 8, 9 and 10 .

Step 3: The interval-valued distribution preference vector is transformed into the weighting preference vector.

Using (9) and (10), let $\mathrm{w}_{1}=[0.08,0.086], \mathrm{w}_{2}=[0.05,0.101], \mathrm{w}_{3}=$ $[0.04,0.072], \mathrm{w}_{4}=0.505, \mathrm{w}_{5}=[0.253,0.272]$. Then, we obtain the weighting preference vector:

$$
\tilde{S}\left(D_{i}\left(A_{l}, B_{g}\right)\right)=\left\{r_{j},\left[\bar{m}_{i}^{-}\left(r_{j}\right), \bar{m}_{i}^{+}\left(r_{j}\right)\right], r_{j} \in\{\succ, \|, \stackrel{\vee}{\|}, \underset{\wedge}{\|} \underset{\wedge}{\|} \approx, \prec\}\right\} .
$$

Step 4: Transform the weighting interval probability is into the interval probability weight.

Supposing the problem is framed in such a way that all consequences are expressed in terms of gain only, based on formulas (13)-(16), let $\gamma=0.61$ for the exponent of the weighting function. Then, the interval probability weights can be obtained, as shown in Tables 11, 12, 13, 14 and 15 .

Step 5: Solve the model (17)-(18) and determine the group preference about process kind pairs of $\mathrm{X}$, denoted as

$$
\begin{aligned}
& S\left(D\left(A_{l}, A_{g}\right)=\left\{r_{j}, m\left(r_{j}\right), r_{j} \in\{\succ,\|,\|,\|,\| \wedge, \approx, \prec\}\right\} ;\right. \\
& \left.A_{l}, A_{g} \in\left\{A_{1}, \ldots, A_{5}\right\}\right\} .
\end{aligned}
$$

$S\left(D\left(A_{l}, A_{g}\right)\right.$ is the group preference distribution vector of the decision preference system

$S=(\mathrm{H}, \mathrm{D})$. The group preference probability distributions are shown in Table 16. 
Step 6: Setting $\sigma=0.02$, determine the binary relation between alternative pair $\left(A_{l}, A_{g}\right): \mathrm{R}^{*}\left(A_{1}, A_{2}\right)=\left\{\underset{\wedge}{\|}, \mathrm{R}^{*}\left(A_{1}, A_{3}\right)=\{\underset{\wedge}{\vee}\}, \mathrm{R}^{*}\left(A_{1}, A_{4}\right)=\{\prec\}, \mathrm{R}^{*}\left(A_{1}, A_{5}\right)=\right.$ $\{\approx, \prec,\|\stackrel{\vee}{\|}\|\}, \mathrm{R}^{*}\left(A_{2}, A_{3}\right)=\{\stackrel{\wedge}{\|} \approx, \prec\}, \mathrm{R}^{*}\left(A_{2}, A_{4}\right)=\left\{\succ, \stackrel{\vee}{\|}, \mathrm{R}^{*}\left(A_{2}, A_{5}\right)=\{\succ\}\right.$,

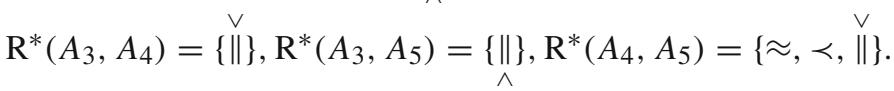

If the set $\mathrm{R}^{*}\left(A_{l}, A_{g}\right)\left(\mathrm{A}_{l}, \mathrm{~A}_{k} \in\left\{A_{1}, \ldots, A_{5}\right\}\right)$ has only one element $r^{*}$, then preference relation $r^{*}$ is identified as the group preference; otherwise, go to the next step.

For the example of scheme pair $\left(\mathrm{A}_{1}, \mathrm{~A}_{3}\right)$, the data shown in Tables $1,2,34$, and 5 were used through Steps 1-5, and we can thus derive the group preference. If $\mathrm{R}^{*}\left(A_{1}, A_{3}\right)=\left\{\|_{\wedge}^{\vee}\right\}$ is established, then the value of Eq. (17) is the minimum and divergence in the decision group is smaller. So, $r^{*}=\|_{\wedge}^{\vee}$ is identified as the group preference for $\left(A_{1}, A_{3}\right)$.

Step 7: Use the priority principle of binary relations to determine the group preference.

If the model (17) has more than one optimal solution, that is, if set $\mathrm{R}^{*}$ has two, three, or four binary relations, then the priority principle of binary relations is used to determine the binary relations between group preference schemes.

For the example of scheme pair $\left(\mathrm{A}_{1}, \mathrm{~A}_{2}\right)$, we can derive the group preference set $\mathrm{R}^{*}\left(A_{1}, A_{5}\right)=\{\underset{\vee}{\approx}, \prec,\|\|$,$\} . Then, using the priority principle on the binary relation$ set, $\{\succ,\|\|,,\|\|,, \approx, \prec\}, \mathrm{r}^{*}=\prec$ is identified as the group preference on $\left(\mathrm{A}_{1}, \mathrm{~A}_{2}\right)$. That is, $\mathrm{A}_{1} \prec \hat{\mathrm{A}_{5}}$ is established.

Step 8: Use the assembly principle of binary relations to determine the group preference.

Using the priority principle to screen the element in $\mathrm{R}^{*}$, if $\mathrm{R}^{*}$ has two priority preference relations $\succ$ and $\prec$, using the assembly principle of Roy and Slowinski (1993), obtain the collective preference for $\left(A_{l}, A_{k}\right)$ (Roy and Slowinski 1993).

Finally, we obtain the group preference for $\left(A_{l}, A_{k}\right)$ as

$\mathrm{A}_{1}\left\|\mathrm{~A}_{2}, \quad A_{1}\right\|_{\wedge}^{\vee} A_{3}, \quad A_{1} \prec A_{4}, \quad A_{1} \prec A_{5}, \quad \mathrm{~A}_{2} \prec \mathrm{A}_{3}, \quad A_{2} \succ A_{4}, \quad A_{2} \succ A_{5}$, $\mathrm{A}_{3} \stackrel{\vee}{\|} \mathrm{A}_{4}, \quad \mathrm{~A}_{3} \| \mathrm{A}_{5}, \quad A_{4} \prec A_{5}$.

If we set $\sigma=0.01$, we obtain the group preference for $\left(A_{l}, A_{k}\right): \mathrm{A}_{1} \|{ }_{\wedge} \mathrm{A}_{2}, A_{1} \underset{\wedge}{\vee} A_{3}$, $A_{1} \prec A_{4}, A_{1} \prec A_{5}, \mathrm{~A}_{2} \approx \mathrm{A}_{3}, A_{2} \stackrel{\vee}{\|} A_{4}, A_{2} \succ A_{5}, \mathrm{~A}_{3}\left\|\mathrm{~A}_{4}, \mathrm{~A}_{3}\right\| \wedge_{\wedge} \mathrm{A}_{5}, A_{4} \prec A_{5}$.

Decision makers can select the optimal process technology from the five programs based on the binary relations between alternative pairs. The optimal process technology is scraper shape (A5) about application analysis in this paper. 
Moreover, from the application analysis, we can see that the comprehensive evaluation has lattice-ordered preference characteristics. A lattice-ordered preference structure can reflect decision makers' actual preferences; it is not dependent on connectivity, but can also satisfy certain rational axioms. For example, the comprehensive evaluation shows that $A_{1} \| A_{3}$; however, $\mathrm{A}_{1}$ and $\mathrm{A}_{3}$ have an 1.u.b. and a g.1.b., that is, $\mathrm{A}_{1} \stackrel{\vee}{\vee} \mathrm{A}_{3}$. Previous literature failed to resolve such problems: Jabeur et al. (2004), Jabeur and Martel (2010) and Amor et al. (2007) concluded only that $A_{1} \| A_{3}$, missing some useful information, it is not conducive to information mining, and thus, has limited significance for scientific decision making.

\section{Conclusion}

Risk GDM methods are widely used in the real decision making process, and decision making based on prospect theory is more in line with people's actual decision-making behavior. Therefore, the purpose of this paper was to provide insight into the combination of DMs' random preference behavior and CPT, especially using uncertain variable to replace accurate number of the binary relation's possibility.

To express and describe decision makers' random preference relations, clearing the decision makers' decision result, we extend preference relations from four varieties $(\{\succ, \|, \approx, \prec\})$ to seven $(\{\succ,\|\|,,\|\|,, \approx, \prec\})$. Second, the interval probability of the binary relation can be more precise. If the weighting interval probability is transformed into the interval probability weight by considering DMs' behavior, then the ER nonlinear optimization model based on preference entropy of the latticeordered preference system is established, and the individual preferences are aggregated by applying the priority rules and the intersection rule, which gives the specific decision-making steps. Finally, the feasibility and effectiveness of the approach proposed in this paper are illustrated through process category selection for green manufacturing.

There are two directions for future research. First, the proposed method can be extended to dynamic environments. Second, the reference points are uncertain in decision analysis.

Acknowledgments The authors thank the anonymous referees for their constructive suggestions. We appreciate the support provided for this paper by the National Natural Science Funds of China (Project Nos. 71471123 and 71071102); and the Fundamental Research Funds for the Central Universities (No. skqy201324).

Open Access This article is distributed under the terms of the Creative Commons Attribution License which permits any use, distribution, and reproduction in any medium, provided the original author(s) and the source are credited.

\section{Appendix}

See Tables 1, 2, 3, 4, 5, 6, 7, 8, 9, 10, 11, 12, 13, 14 and 15 . 
Table 1 The interval-valued distribution preference vector under expert D1

\begin{tabular}{|c|c|c|c|c|c|c|c|}
\hline D1 & $\succ$ & $\|$ & $\stackrel{V}{\|}$ & $\underset{\wedge}{\|}$ & $\begin{array}{l}\vee \\
\| \\
\wedge\end{array}$ & $\approx$ & $\prec$ \\
\hline$(\mathrm{A} 1, \mathrm{~A} 2)$ & {$[0.08,0.54]$} & {$[0.14,0.88]$} & {$[0.34,0.58]$} & {$[0.05,0.30]$} & {$[0.06,0.94]$} & {$[0.13,0.52]$} & {$[0.12,0.73]$} \\
\hline (A1, A3) & {$[0.07,0.27]$} & {$[0.01,0.08]$} & {$[0.01,0.31]$} & {$[0.34,0.42]$} & {$[0.33,0.70]$} & {$[0.22,0.55]$} & {$[0.00,0.29]$} \\
\hline (A1, A4) & {$[0.03,1.00]$} & {$[0.01,0.51]$} & {$[0.08,0.58]$} & {$[0.04,0.88]$} & {$[0.15,0.84]$} & {$[0.03,0.14]$} & {$[0.60,0.99]$} \\
\hline (A1, A5) & {$[0.03,0.27]$} & {$[0.11,0.52]$} & {$[0.2,0.49]$} & {$[0.02,0.82]$} & {$[0.07,0.83]$} & {$[0.27,0.78]$} & {$[0.22,0.97]$} \\
\hline (A2, A3) & {$[0.02,0.51]$} & {$[0.37,0.70]$} & {$[0.14,0.78]$} & {$[0.03,0.15]$} & {$[0.03,0.17]$} & {$[0.26,0.48]$} & {$[0.14,0.55]$} \\
\hline (A2, A4) & {$[0.01,0.24]$} & {$[0.02,0.13]$} & {$[0.39,0.58]$} & {$[0.27,0.51]$} & {$[0.03,0.21]$} & {$[0.12,0.23]$} & {$[0.16,0.45]$} \\
\hline$(\mathrm{A} 2, \mathrm{~A} 5)$ & {$[0.12,0.59]$} & {$[0.09,0.28]$} & {$[0.15,0.47]$} & {$[0.14,0.28]$} & {$[0.17,0.57]$} & {$[0.08,0.26]$} & {$[0.17,0.25]$} \\
\hline (A3, A4) & {$[0.13,0.53]$} & {$[0.23,0.68]$} & {$[0.03,0.50]$} & {$[0.40,0.49]$} & {$[0.06,0.60]$} & {$[0.02,0.19]$} & {$[0.13,0.47]$} \\
\hline (A3, A5) & {$[0.11,0.31]$} & {$[0.13,0.51]$} & {$[0.01,0.09]$} & {$[0.30,0.55]$} & {$[0.09,0.34]$} & {$[0.07,0.22]$} & {$[0.15,0.39]$} \\
\hline (A4, A5) & {$[0.06,0.57]$} & {$[0.05,0.30]$} & {$[0.07,0.17]$} & {$[0.09,0.19]$} & {$[0.28,0.33]$} & {$[0.16,0.60]$} & {$[0.10,0.35]$} \\
\hline
\end{tabular}

Table 2 The interval-valued distribution preference vector under expert D2

\begin{tabular}{|c|c|c|c|c|c|c|c|}
\hline D2 & $\succ$ & $\|$ & $\begin{array}{l}V \\
\|\end{array}$ & $\underset{\wedge}{\|}$ & $\begin{array}{l}\vee \\
\| \\
\wedge\end{array}$ & $\approx$ & $\prec$ \\
\hline$(\mathrm{A} 1, \mathrm{~A} 2)$ & {$[0.36,0.41]$} & {$[0.02,0.18]$} & {$[0.07,0.27]$} & {$[0.12,0.27]$} & {$[0.14,0.88]$} & {$[0.07,0.38]$} & {$[0.22,0.78]$} \\
\hline (A1, A3) & {$[0.12,0.80]$} & {$[0.38,0.68]$} & {$[0.10,0.67]$} & {$[0.12,0.49]$} & {$[0.04,0.42]$} & {$[0.17,0.81]$} & {$[0.04,0.24]$} \\
\hline (A1, A4) & {$[0.04,0.84]$} & {$[0.10,0.57]$} & {$[0.16,0.56]$} & {$[0.08,0.86]$} & {$[0.08,0.34]$} & {$[0.01,0.85]$} & {$[0.51,0.86]$} \\
\hline (A1, A5) & {$[0.08,0.53]$} & {$[0.25,0.76]$} & {$[0.15,0.48]$} & {$[0.13,0.61]$} & {$[0.08,0.93]$} & {$[0.13,0.38]$} & {$[0.17,0.54]$} \\
\hline (A2, A3) & {$[0.25,0.68]$} & {$[0.20,0.36]$} & {$[0.10,0.48]$} & {$[0.08,0.84]$} & {$[0.21,0.79]$} & {$[0.03,0.09]$} & {$[0.07,0.33]$} \\
\hline$(\mathrm{A} 2, \mathrm{~A} 4)$ & {$[0.09,0.52]$} & {$[0.04,0.16]$} & {$[0.10,0.14]$} & {$[0.01,0.22]$} & {$[0.02,0.66]$} & {$[0.18,0.28]$} & {$[0.45,0.51]$} \\
\hline$(\mathrm{A} 2, \mathrm{~A} 5)$ & {$[0.33,0.51]$} & {$[0.33,0.57]$} & {$[0.02,0.87]$} & {$[0.02,0.06]$} & {$[0.15,0.68]$} & {$[0.04,0.47]$} & {$[0.02,0.38]$} \\
\hline (A3, A4) & {$[0.06,0.10]$} & {$[0.11,0.60]$} & {$[0.01,0.36]$} & {$[0.22,0.39]$} & {$[0.23,0.38]$} & {$[0.15,0.46]$} & {$[0.21,0.69]$} \\
\hline$(\mathrm{A} 3, \mathrm{~A} 5)$ & {$[0.04,0.20]$} & {$[0.24,0.79]$} & {$[0.16,0.87]$} & {$[0.16,0.42]$} & {$[0.24,0.26]$} & {$[0.08,0.30]$} & {$[0.08,0.47]$} \\
\hline$(\mathrm{A} 4, \mathrm{~A} 5)$ & {$[0.19,0.57]$} & {$[0.09,0.35]$} & {$[0.02,0.55]$} & {$[0.04,0.26]$} & {$[0.25,0.81]$} & {$[0.21,0.70]$} & {$[0.10,0.34]$} \\
\hline
\end{tabular}

Table 3 The interval-valued distribution preference vector under expert D3

\begin{tabular}{|c|c|c|c|c|c|c|c|}
\hline D3 & $\succ$ & $\|$ & $\begin{array}{l}V \\
\|\end{array}$ & $\underset{\wedge}{\|}$ & $\begin{array}{l}\vee \\
\| \\
\wedge\end{array}$ & $\approx$ & $\prec$ \\
\hline$(\mathrm{A} 1, \mathrm{~A} 2)$ & {$[0.18,0.87]$} & {$[0.22,0.39]$} & {$[0.07,0.13]$} & {$[0.11,0.79]$} & {$[0.08,0.23]$} & {$[0.18,0.31]$} & {$[0.08,0.50]$} \\
\hline (A1, A3) & {$[0.26,0.28]$} & {$[0.03,0.52]$} & {$[0.18,0.94]$} & {$[0.23,0.91]$} & {$[0.17,0.20]$} & {$[0.00,0.41]$} & {$[0.03,0.71]$} \\
\hline (A1, A4) & {$[0.13,1.00]$} & {$[0.02,0.90]$} & {$[0.01,0.14]$} & {$[0.54,0.87]$} & {$[0.09,0.25]$} & {$[0.03,0.22]$} & {$[0.14,0.51]$} \\
\hline (A1, A5) & {$[0.06,0.87]$} & {$[0.01,0.63]$} & {$[0.03,0.89]$} & {$[0.07,0.94]$} & {$[0.49,0.60]$} & {$[0.22,0.33]$} & {$[0.04,0.22]$} \\
\hline (A2, A3) & {$[0.19,0.62]$} & {$[0.02,0.44]$} & {$[0.05,0.25]$} & {$[0.19,0.99]$} & {$[0.04,0.35]$} & {$[0.40,0.54]$} & {$[0.06,0.38]$} \\
\hline (A2, A4) & {$[0.05,0.86]$} & {$[0.07,0.11]$} & {$[0.01,0.57]$} & {$[0.38,0.40]$} & {$[0.11,0.33]$} & {$[0.15,0.21]$} & {$[0.12,0.49]$} \\
\hline (A2, A5) & {$[0.13,0.40]$} & {$[0.19,0.55]$} & {$[0.19,0.41]$} & {$[0.01,0.60]$} & {$[0.07,0.38]$} & {$[0.05,0.10]$} & {$[0.27,0.78]$} \\
\hline$(\mathrm{A} 3, \mathrm{~A} 4)$ & {$[0.03,0.42]$} & {$[0.01,0.50]$} & {$[0.08,0.52]$} & {$[0.14,0.48]$} & {$[0.25,0.59]$} & {$[0.21,0.73]$} & {$[0.07,0.31]$} \\
\hline (A3, A5) & {$[0.29,0.40]$} & {$[0.21,0.69]$} & {$[0.02,0.49]$} & {$[0.21,0.68]$} & {$[0.05,0.34]$} & {$[0.04,0.46]$} & {$[0.04,0.32]$} \\
\hline$(\mathrm{A} 4, \mathrm{~A} 5)$ & {$[0.00,0.13]$} & {$[0.11,0.50]$} & {$[0.01,0.38]$} & {$[0.18,0.38]$} & {$[0.23,0.42]$} & {$[0.10,0.51]$} & {$[0.26,0.55]$} \\
\hline
\end{tabular}


Table 4 The interval-valued distribution preference vector under expert D4

\begin{tabular}{|c|c|c|c|c|c|c|c|}
\hline D4 & $\succ$ & $\|$ & $\|$ & $\stackrel{\wedge}{\|}$ & $\stackrel{\|}{\|}$ & $\approx$ & $\prec$ \\
\hline$(\mathrm{A} 1, \mathrm{~A} 2)$ & {$[0.13,0.22]$} & {$[0.01,0.57]$} & {$[0.04,0.90]$} & {$[0.28,0.64]$} & {$[0.01,0.81]$} & {$[0.21,0.51]$} & {$[0.10,0.31]$} \\
\hline (A1, A3) & {$[0.10,0.36]$} & {$[0.25,0.61]$} & {$[0.04,0.37]$} & {$[0.01,0.05]$} & {$[0.09,0.25]$} & {$[0.08,0.27]$} & {$[0.40,0.48]$} \\
\hline$(\mathrm{A} 1, \mathrm{~A} 4)$ & {$[0.31,0.62]$} & {$[0.10,0.53]$} & {$[0.30,0.57]$} & {$[0.08,0.15]$} & {$[0.01,0.18]$} & {$[0.01,0.04]$} & {$[0.19,0.32]$} \\
\hline (A1, A5) & {$[0.04,0.55]$} & {$[0.01,0.39]$} & {$[0.22,0.49]$} & {$[0.01,0.30]$} & {$[0.15,0.59]$} & {$[0.21,0.29]$} & {$[0.15,0.36]$} \\
\hline (A2, A3) & {$[0.03,0.37]$} & {$[0.01,0.42]$} & {$[0.08,0.22]$} & {$[0.37,0.99]$} & {$[0.13,0.17]$} & {$[0.19,0.36]$} & {$[0.09,0.46]$} \\
\hline$(\mathrm{A} 2, \mathrm{~A} 4)$ & {$[0.26,0.97]$} & {$[0.09,0.51]$} & {$[0.08,0.33]$} & {$[0.08,0.50]$} & {$[0.01,0.84]$} & {$[0.17,0.83]$} & {$[0.12,0.29]$} \\
\hline (A2, A5) & {$[0.35,0.37]$} & {$[0.04,0.15]$} & {$[0.01,0.07]$} & {$[0.16,0.25]$} & {$[0.03,0.53]$} & {$[0.16,0.39]$} & {$[0.14,0.69]$} \\
\hline (A3, A4) & {$[0.03,0.39]$} & {$[0.03,0.45]$} & {$[0.27,0.58]$} & {$[0.12,0.57]$} & {$[0.19,0.75]$} & {$[0.02,0.67]$} & {$[0.00,0.53]$} \\
\hline (A3, A5) & {$[0.02,0.32]$} & {$[0.02,0.11]$} & {$[0.09,0.34]$} & {$[0.28,0.40]$} & {$[0.07,0.54]$} & {$[0.03,0.55]$} & {$[0.24,0.60]$} \\
\hline (A4, A5) & {$[0.05,0.36]$} & {$[0.00,0.21]$} & {$[0.13,0.43]$} & {$[0.24,0.44]$} & {$[0.12,0.56]$} & {$[0.11,0.29]$} & {$[0.32,0.58]$} \\
\hline
\end{tabular}

Table 5 The interval-valued distribution preference vector under expert D5

\begin{tabular}{|c|c|c|c|c|c|c|c|}
\hline D5 & $\succ$ & $\|$ & $\|$ & $\stackrel{\|}{\|}$ & $\stackrel{\vee}{\|}$ & $\approx$ & $\prec$ \\
\hline$(\mathrm{A} 1, \mathrm{~A} 2)$ & {$[0.09,0.54]$} & {$[0.07,0.71]$} & {$[0.02,0.04]$} & {$[0.20,0.73]$} & {$[0.37,0.88]$} & {$[0.13,0.42]$} & {$[0.03,0.64]$} \\
\hline (A1, A3) & {$[0.18,0.23]$} & {$[0.04,0.63]$} & {$[0.09,0.35]$} & {$[0.13,0.46]$} & {$[0.45,0.78]$} & {$[0.05,0.23]$} & {$[0.03,0.41]$} \\
\hline$(\mathrm{A} 1, \mathrm{~A} 4)$ & {$[0.02,0.40]$} & {$[0.08,0.59]$} & {$[0.07,0.58]$} & {$[0.00,0.21]$} & {$[0.25,0.45]$} & {$[0.16,0.56]$} & {$[0.29,0.70]$} \\
\hline (A1, A5) & {$[0.02,0.63]$} & {$[0.34,0.64]$} & {$[0.02,0.40]$} & {$[0.30,0.94]$} & {$[0.06,0.32]$} & {$[0.04,0.67]$} & {$[0.20,0.22]$} \\
\hline (A2, A3) & {$[0.00,0.56]$} & {$[0.07,0.80]$} & {$[0.20,0.90]$} & {$[0.05,0.46]$} & {$[0.09,0.36]$} & {$[0.13,0.51]$} & {$[0.37,0.72]$} \\
\hline$(\mathrm{A} 2, \mathrm{~A} 4)$ & {$[0.06,0.56]$} & {$[0.08,0.83]$} & {$[0.22,0.82]$} & {$[0.00,0.16]$} & {$[0.18,0.41]$} & {$[0.02,0.12]$} & {$[0.01,0.39]$} \\
\hline (A2, A5) & {$[0.31,0.79]$} & {$[0.19,0.61]$} & {$[0.04,0.23]$} & {$[0.02,0.62]$} & {$[0.36,0.81]$} & {$[0.04,0.32]$} & {$[0.02,0.33]$} \\
\hline (A3, A4) & {$[0.09,0.34]$} & {$[0.02,0.47]$} & {$[0.38,0.52]$} & {$[0.09,0.13]$} & {$[0.11,0.62]$} & {$[0.03,0.13]$} & {$[0.16,0.52]$} \\
\hline (A3, A5) & {$[0.02,0.32]$} & {$[0.13,0.46]$} & {$[0.14,0.56]$} & {$[0.27,0.53]$} & {$[0.20,0.64]$} & {$[0.15,0.65]$} & {$[0.07,0.33]$} \\
\hline (A4, A5) & {$[0.27,0.67]$} & {$[0.02,0.38]$} & {$[0.28,0.58]$} & {$[0.04,0.25]$} & {$[0.03,0.48]$} & {$[0.31,0.77]$} & {$[0.05,0.36]$} \\
\hline
\end{tabular}

Table 6 The more precise interval probability under expert D1

\begin{tabular}{|c|c|c|c|c|c|c|c|}
\hline D1 & $\succ$ & $\|$ & $\begin{array}{l}V \\
\|\end{array}$ & $\underset{\wedge}{\|}$ & $\begin{array}{l}\vee \\
\| \\
\wedge\end{array}$ & $\approx$ & $\prec$ \\
\hline
\end{tabular}

$(\mathrm{A} 1, \mathrm{~A} 2) \quad[0.08,0.16] \quad[0.14,0.22] \quad[0.34,0.42] \quad[0.05,0.13] \quad[0.06,0.14] \quad[0.13,0.21] \quad[0.12,0.20]$ $\begin{array}{lllllllll}(\mathrm{A} 1, \mathrm{~A} 3) & {[0.07,0.09]} & {[0.01,0.03]} & {[0.01,0.03]} & {[0.34,0.36]} & {[0.33,0.35]} & {[0.22,0.24]} & {[0.00,0.02]}\end{array}$ $\begin{array}{lllllllll}(\mathrm{A} 1, \mathrm{~A} 4) & {[0.03,0.09]} & {[0.01,0.07]} & {[0.08,0.14]} & {[0.04,0.10]} & {[0.15,0.21]} & {[0.03,0.09]} & {[0.60,0.66]}\end{array}$ $(\mathrm{A} 1, \mathrm{~A} 5) \quad[0.03,0.11][0.11,0.19] \quad[0.20,0.28][0.02,0.10] \quad[0.07,0.15] \quad[0.27,0.35] \quad[0.22,0.30]$ $\begin{array}{lllllllll}(\mathrm{A} 2, \mathrm{~A} 3) & {[0.02,0.03]} & {[0.37,0.38]} & {[0.14,0.15]} & {[0.03,0.04]} & {[0.03,0.04]} & {[0.26,0.27]} & {[0.14,0.15]}\end{array}$ $\begin{array}{llllllll}(\mathrm{A} 2, \mathrm{~A} 4) & {[0.01,0.01]} & {[0.02,0.02]} & {[0.39,0.39]} & {[0.27,0.27]} & {[0.03,0.03]} & {[0.12,0.12]} & {[0.16,0.16]}\end{array}$ $\begin{array}{lllllllll}(\mathrm{A} 2, \mathrm{~A} 5) & {[0.12,0.20]} & {[0.09,0.17]} & {[0.15,0.23]} & {[0.14,0.22]} & {[0.17,0.25]} & {[0.08,0.16]} & {[0.17,0.25]}\end{array}$ $\begin{array}{lllllllll}(\mathrm{A} 3, \mathrm{~A} 4) & {[0.13,0.13]} & {[0.23,0.23]} & {[0.03,0.03]} & {[0.40,0.40]} & {[0.06,0.06]} & {[0.02,0.02]} & {[0.13,0.13]}\end{array}$ $\begin{array}{llllllll}(\mathrm{A} 3, \mathrm{~A} 5) & {[0.11,0.25]} & {[0.13,0.27]} & {[0.01,0.15]} & {[0.30,0.44]} & {[0.09,0.23]} & {[0.07,0.21]} & {[0.15,0.29]}\end{array}$ $(\mathrm{A} 4, \mathrm{~A} 5) \quad[0.06,0.25] \quad[0.05,0.24] \quad[0.07,0.17] \quad[0.09,0.19] \quad[0.28,0.33] \quad[0.16,0.35] \quad[0.10,0.29]$ 
Table 7 The more precise interval probability under expert D2

\begin{tabular}{|c|c|c|c|c|c|c|c|}
\hline D2 & $\succ$ & $\|$ & $\begin{array}{l}V \\
\|\end{array}$ & $\underset{\wedge}{\|}$ & $\begin{array}{l}\stackrel{V}{\|} \\
\wedge\end{array}$ & $\approx$ & $\prec$ \\
\hline$(\mathrm{A} 1, \mathrm{~A} 2)$ & {$[0.36,0.36]$} & {$[0.02,0.02]$} & {$[0.07,0.07]$} & {$[0.12,0.12]$} & {$[0.14,0.14]$} & {$[0.07,0.07]$} & {$[0.22,0.22]$} \\
\hline (A1, A3) & {$[0.12,0.15]$} & {$[0.38,0.41]$} & {$[0.10,0.13]$} & {$[0.12,0.15]$} & {$[0.04,0.07]$} & {$[0.17,0.20]$} & {$[0.04,0.07]$} \\
\hline$(\mathrm{A} 1, \mathrm{~A} 4)$ & {$[0.04,0.06]$} & {$[0.10,0.12]$} & {$[0.16,0.18]$} & {$[0.08,0.10]$} & {$[0.08,0.10]$} & {$[0.01,0.03]$} & {$[0.51,0.53]$} \\
\hline (A1, A5) & {$[0.08,0.09]$} & {$[0.25,0.26]$} & {$[0.15,0.16]$} & {$[0.13,0.14]$} & {$[0.08,0.09]$} & {$[0.13,0.14]$} & {$[0.17,0.18]$} \\
\hline (A2, A3) & {$[0.25,0.31]$} & {$[0.20,0.26]$} & {$[0.10,0.16]$} & {$[0.08,0.14]$} & {$[0.21,0.27]$} & {$[0.03,0.09]$} & {$[0.07,0.13]$} \\
\hline (A2, A4) & {$[0.09,0.20]$} & {$[0.04,0.15]$} & {$[0.10,0.14]$} & {$[0.01,0.12]$} & {$[0.02,0.13]$} & {$[0.18,0.28]$} & {$[0.45,0.51]$} \\
\hline (A2, A5) & {$[0.33,0.42]$} & {$[0.33,0.42]$} & {$[0.02,0.21]$} & {$[0.02,0.06]$} & {$[0.15,0.24]$} & {$[0.04,0.23]$} & {$[0.02,0.11]$} \\
\hline (A3, A4) & {$[0.06,0.07]$} & {$[0.11,0.12]$} & {$[0.01,0.02]$} & {$[0.22,0.23]$} & {$[0.23,0.24]$} & {$[0.15,0.16]$} & {$[0.21,0.22]$} \\
\hline (A3, A5) & {$[0.04,0.04]$} & {$[0.24,0.24]$} & {$[0.16,0.16]$} & {$[0.16,0.16]$} & {$[0.24,0.24]$} & {$[0.08,0.08]$} & {$[0.08,0.08]$} \\
\hline (A4, A5) & {$[0.19,0.29]$} & {$[0.09,0.19]$} & {$[0.02,0.12]$} & {$[0.04,0.14]$} & {$[0.25,0.35]$} & {$[0.21,0.31]$} & {$[0.10,0.20]$} \\
\hline
\end{tabular}

Table 8 The more precise interval probability under expert D3

\begin{tabular}{|c|c|c|c|c|c|c|c|}
\hline D3 & $\succ$ & $\|$ & $\begin{array}{l}V \\
\|\end{array}$ & $\stackrel{\|}{\wedge}$ & $\begin{array}{l}\vee \\
\| \\
\wedge\end{array}$ & $\approx$ & $\prec$ \\
\hline$(\mathrm{A} 1, \mathrm{~A} 2)$ & {$[0.18,0.26]$} & {$[0.22,0.30]$} & {$[0.07,0.13]$} & {$[0.11,0.19]$} & {$[0.08,0.16]$} & {$[0.18,0.26]$} & {$[0.08,0.16]$} \\
\hline (A1, A3) & {$[0.26,0.28]$} & {$[0.03,0.13]$} & {$[0.18,0.28]$} & {$[0.23,0.33]$} & {$[0.17,0.20]$} & {$[0.00,0.10]$} & {$[0.03,0.13]$} \\
\hline (A1, A4) & {$[0.13,0.17]$} & {$[0.02,0.06]$} & {$[0.01,0.05]$} & {$[0.54,0.58]$} & {$[0.09,0.13]$} & {$[0.03,0.07]$} & {$[0.14,0.18]$} \\
\hline (A1, A5) & {$[0.06,0.14]$} & {$[0.01,0.09]$} & {$[0.03,0.11]$} & {$[0.07,0.15]$} & {$[0.49,0.57]$} & {$[0.22,0.30]$} & {$[0.04,0.12]$} \\
\hline (A2, A3) & {$[0.19,0.24]$} & {$[0.02,0.07]$} & {$[0.05,0.10]$} & {$[0.19,0.24]$} & {$[0.04,0.09]$} & {$[0.40,0.45]$} & {$[0.06,0.10]$} \\
\hline (A2, A4) & {$[0.05,0.16]$} & {$[0.07,0.11]$} & {$[0.01,0.12]$} & {$[0.38,0.40]$} & {$[0.11,0.22]$} & {$[0.15,0.21]$} & {$[0.12,0.23]$} \\
\hline (A2, A5) & {$[0.13,0.22]$} & {$[0.19,0.28]$} & {$[0.19,0.28]$} & {$[0.01,0.10]$} & {$[0.07,0.16]$} & {$[0.05,0.10]$} & {$[0.27,0.36]$} \\
\hline (A3, A4) & {$[0.03,0.24]$} & {$[0.01,0.22]$} & {$[0.08,0.29]$} & {$[0.14,0.35]$} & {$[0.25,0.46]$} & {$[0.21,0.42]$} & {$[0.07,0.28]$} \\
\hline (A3, A5) & {$[0.29,0.40]$} & {$[0.21,0.35]$} & {$[0.02,0.16]$} & {$[0.21,0.35]$} & {$[0.05,0.19]$} & {$[0.04,0.18]$} & {$[0.04,0.18]$} \\
\hline (A4, A5) & {$[0.00,0.11]$} & {$[0.11,0.22]$} & {$[0.01,0.12]$} & {$[0.18,0.29]$} & {$[0.23,0.34]$} & {$[0.10,0.21]$} & {$[0.26,0.37]$} \\
\hline
\end{tabular}

Table 9 The more precise interval probability under expert D4

\begin{tabular}{|c|c|c|c|c|c|c|c|}
\hline D4 & $\succ$ & $\|$ & $\begin{array}{l}V \\
\|\end{array}$ & $\underset{\wedge}{\|}$ & $\begin{array}{l}\vee \\
\| \\
\wedge\end{array}$ & $\approx$ & $\prec$ \\
\hline$(\mathrm{A} 1, \mathrm{~A} 2)$ & {$[0.13,0.22]$} & {$[0.01,0.23]$} & {$[0.04,0.26]$} & {$[0.28,0.50]$} & {$[0.01,0.23]$} & {$[0.21,0.43]$} & {$[0.10,0.31]$} \\
\hline (A1, A3) & {$[0.10,0.13]$} & {$[0.25,0.28]$} & {$[0.04,0.07]$} & {$[0.01,0.04]$} & {$[0.09,0.12$} & {$[0.08,0.11]$} & {$[0.40,0.43]$} \\
\hline (A1, A4) & {$[0.31,0.31]$} & {$[0.10,0.10]$} & {$[0.30,0.30]$} & {$[0.08,0.08]$} & {$[0.01,0.01]$} & {$[0.01,0.01]$} & {$[0.19,0.19]$} \\
\hline (A1, A5) & {$[0.04,0.25]$} & {$[0.01,0.22]$} & {$[0.22,0.43]$} & {$[0.01,0.22]$} & {$[0.15,0.36]$} & {$[0.21,0.29]$} & {$[0.15,0.36]$} \\
\hline (A2, A3) & {$[0.03,0.13]$} & {$[0.01,0.11]$} & {$[0.08,0.18]$} & {$[0.37,0.47]$} & {$[0.13,0.17]$} & {$[0.19,0.29]$} & {$[0.09,0.19]$} \\
\hline$(\mathrm{A} 2, \mathrm{~A} 4)$ & {$[0.26,0.45]$} & {$[0.09,0.28]$} & {$[0.08,0.27]$} & {$[0.08,0.27]$} & {$[0.01,0.20]$} & {$[0.17,0.36]$} & {$[0.12,0.29]$} \\
\hline$(\mathrm{A} 2, \mathrm{~A} 5)$ & {$[0.35,0.37]$} & {$[0.04,0.15]$} & {$[0.01,0.07]$} & {$[0.16,0.25]$} & {$[0.03,0.14]$} & {$[0.16,0.27]$} & {$[0.14,0.25]$} \\
\hline (A3, A4) & {$[0.03,0.37]$} & {$[0.03,0.37]$} & {$[0.27,0.58]$} & {$[0.12,0.46]$} & {$[0.19,0.53]$} & {$[0.02,0.36]$} & {$[0.00,0.34]$} \\
\hline (A3, A5) & {$[0.02,0.27]$} & {$[0.02,0.11]$} & {$[0.09,0.34]$} & {$[0.28,0.40]$} & {$[0.07,0.32]$} & {$[0.03,0.28]$} & {$[0.24,0.49]$} \\
\hline (A4, A5) & {$[0.05,0.08]$} & {$[0.00,0.03]$} & {$[0.13,0.16]$} & {$[0.24,0.27]$} & {$[0.12,0.15]$} & {$[0.11,0.14]$} & {$[0.32,0.35]$} \\
\hline
\end{tabular}


Table 10 The more precise interval probability under expert D5

\begin{tabular}{|c|c|c|c|c|c|c|c|}
\hline D5 & $\succ$ & $\|$ & $\stackrel{V}{\|}$ & $\stackrel{\|}{\wedge}$ & $\begin{array}{l}\vee \\
\wedge \\
\wedge\end{array}$ & $\approx$ & $\prec$ \\
\hline$(\mathrm{A} 1, \mathrm{~A} 2)$ & {$[0.09,0.18]$} & {$[0.07,0.16]$} & {$[0.02,0.04]$} & {$[0.20,0.29]$} & {$[0.37,0.46]$} & {$[0.13,0.22]$} & {$[0.03,0.12]$} \\
\hline (A1, A3) & {$[0.18,0.21]$} & {$[0.04,0.07]$} & {$[0.09,0.12]$} & {$[0.13,0.16]$} & {$[0.45,0.48]$} & {$[0.05,0.08]$} & {$[0.03,0.06]$} \\
\hline (A1, A4) & {$[0.02,0.15]$} & {$[0.08,0.21]$} & {$[0.07,0.20]$} & {$[0.00,0.13]$} & {$[0.25,0.38]$} & {$[0.16,0.29]$} & {$[0.29,0.42]$} \\
\hline (A1, A5) & {$[0.02,0.04]$} & {$[0.34,0.36]$} & {$[0.02,0.04]$} & {$[0.30,0.32]$} & {$[0.06,0.08]$} & {$[0.04,0.06]$} & {$[0.20,0.22]$} \\
\hline$(\mathrm{A} 2, \mathrm{~A} 3)$ & {$[0.00,0.09]$} & {$[0.07,0.16]$} & {$[0.20,0.29]$} & {$[0.05,0.14]$} & {$[0.09,0.18]$} & {$[0.13,0.22]$} & {$[0.37,0.46]$} \\
\hline (A2, A4) & {$[0.06,0.49]$} & {$[0.08,0.51]$} & {$[0.22,0.65]$} & {$[0.00,0.16]$} & {$[0.18,0.41]$} & {$[0.02,0.12]$} & {$[0.01,0.39]$} \\
\hline (A2, A5) & {$[0.31,0.33]$} & {$[0.19,0.21]$} & {$[0.04,0.06]$} & {$[0.02,0.04]$} & {$[0.36,0.38]$} & {$[0.04,0.06]$} & {$[0.02,0.04]$} \\
\hline (A3, A4) & {$[0.09,0.21]$} & {$[0.02,0.14]$} & {$[0.38,0.50]$} & {$[0.09,0.13]$} & {$[0.11,0.23]$} & {$[0.03,0.13]$} & {$[0.16,0.28]$} \\
\hline (A3, A5) & {$[0.02,0.04]$} & {$[0.13,0.15]$} & {$[0.14,0.16]$} & {$[0.27,0.29]$} & {$[0.20,0.22]$} & {$[0.15,0.17]$} & {$[0.07,0.09]$} \\
\hline (A4, A5) & {$[0.27,0.27]$} & {$[0.02,0.02]$} & {$[0.28,0.28]$} & {$[0.04,0.04]$} & {$[0.03,0.03]$} & {$[0.31,0.31]$} & {$[0.05,0.05]$} \\
\hline
\end{tabular}

Table 11 The interval probability weights under expert D1

\begin{tabular}{|c|c|c|c|c|c|c|c|}
\hline D1 & $\succ$ & $\|$ & $\begin{array}{l}V \\
\|\end{array}$ & $\stackrel{\|}{\wedge}$ & $\begin{array}{l}\vee \\
\| \\
\wedge\end{array}$ & $\approx$ & $\prec$ \\
\hline$(\mathrm{A} 1, \mathrm{~A} 2)$ & {$[0.05,0.07]$} & {$[0.06,0.09]$} & {$[0.11,0.13]$} & {$[0.03,0.06]$} & {$[0.04,0.07]$} & {$[0.06,0.09]$} & {$[0.06,0.08]$} \\
\hline (A1, A3) & {$[0.04,0.05]$} & {$[0.01,0.03]$} & {$[0.01,0.03]$} & {$[0.11,0.12]$} & {$[0.11,0.12]$} & {$[0.08,0.09]$} & {$[0,0.02]$} \\
\hline (A1, A4) & {$[0.03,0.05]$} & {$[0.01,0.04]$} & {$[0.05,0.07]$} & {$[0.03,0.05]$} & {$[0.07,0.09]$} & {$[0.03,0.05]$} & {$[0.15,0.17]$} \\
\hline (A1, A5) & {$[0.03,0.03]$} & {$[0.03,0.08]$} & {$[0.08,0.10]$} & {$[0.02,0.05]$} & {$[0.04,0.07]$} & {$[0.10,0.12]$} & {$[0.08,0.11]$} \\
\hline (A2, A3) & {$[0.02,0.03]$} & {$[0.11,0.12]$} & {$[0.06,0.07]$} & {$[0.03,0.03]$} & {$[0.03,0.03]$} & {$[0.09,0.10]$} & {$[0.06,0.07]$} \\
\hline (A2, A4) & {$[0.01,0.01]$} & {$[0.02,0.02]$} & {$[0.12,0.12]$} & {$[0.10,0.10]$} & {$[0.03,0.03]$} & {$[0.06,0.06]$} & {$[0.07,0.07]$} \\
\hline (A2, A5) & {$[0.06,0.08]$} & {$[0.05,0.08]$} & {$[0.07,0.09]$} & {$[0.06,0.09]$} & {$[0.07,0.09]$} & {$[0.05,0.07]$} & {$[0.07,0.09]$} \\
\hline (A3, A4) & {$[0.06,0.06]$} & {$[0.09,0.09]$} & {$[0.03,0.03]$} & {$[0.12,0.13]$} & {$[0.04,0.04]$} & {$[0.02,0.02]$} & {$[0.06,0.06]$} \\
\hline (A3, A5) & {$[0.06,0.09]$} & {$[0.06,0.10]$} & {$[0.01,0.07]$} & {$[0.10,0.13]$} & {$[0.05,0.09]$} & {$[0.04,0.05]$} & {$[0.07,0.10]$} \\
\hline (A4, A5) & {$[0.04,0.09]$} & {$[0.03,0.09]$} & {$[0.04,0.08]$} & {$[0.05,0.08]$} & {$[0.10,0.11]$} & {$[0.07,0.12]$} & {$[0.05,0.10]$} \\
\hline
\end{tabular}

Table 12 The interval probability weights under expert D2

\begin{tabular}{|c|c|c|c|c|c|c|c|}
\hline D2 & $\succ$ & $\|$ & $\begin{array}{l}V \\
\|\end{array}$ & $\stackrel{\|}{\|}$ & $\underset{\wedge}{\stackrel{\vee}{\|}}$ & $\approx$ & $\prec$ \\
\hline
\end{tabular}

$(\mathrm{A} 1, \mathrm{~A} 2) \quad[0.09,0.13] \quad[0.01,0.02] \quad[0.03,0.05] \quad[0.04,0.07] \quad[0.05,0.07] \quad[0.03,0.05] \quad[0.06,0.10]$ $\begin{array}{llllllllll}(\mathrm{A} 1, \mathrm{~A} 3) & {[0.04,0.08]} & {[0.09,0.14]} & {[0.04,0.07]} & {[0.04,0.08]} & {[0.02,0.05]} & {[0.05,0.09]} & {[0.02,0.05]}\end{array}$ $\begin{array}{llllllllll}(\mathrm{A} 1, \mathrm{~A} 4) & {[0.02,0.04]} & {[0.04,0.07]} & {[0.05,0.09]} & {[0.03,0.06]} & {[0.03,0.06]} & {[0.01,0.03]} & {[0.10,0.16]}\end{array}$ $(\mathrm{A} 1, \mathrm{~A} 5) \quad[0.03,0.06][0.07,0.11] \quad[0.05,0.08] \quad[0.05,0.07] \quad[0.03,0.06] \quad[0.05,0.07] \quad[0.05,0.09]$ $\begin{array}{llllllllll}(\mathrm{A} 2, \mathrm{~A} 3) & {[0.07,0.12]} & {[0.06,0.11]} & {[0.04,0.08]} & {[0.03,0.07]} & {[0.06,0.11]} & {[0.02,0.06]} & {[0.03,0.07]}\end{array}$ $\begin{array}{llllllll}(\mathrm{A} 2, \mathrm{~A} 4) & {[0.04,0.09]} & {[0.02,0.08]} & {[0.04,0.07]} & {[0.01,0.07]} & {[0.01,0.07]} & {[0.06,0.11]} & {[0.10,0.16]}\end{array}$ $\begin{array}{llllllll}(\mathrm{A} 2, \mathrm{~A} 5) & {[0.08,0.14]} & {[0.08,0.14]} & {[0.01,0.09]} & {[0.01,0.04]} & {[0.05,0.10]} & {[0.02,0.10]} & {[0.01,0.06]}\end{array}$ $\begin{array}{llllllllll}(\mathrm{A} 3, \mathrm{~A} 4) & {[0.03,0.05]} & {[0.04,0.07]} & {[0.01,0.02]} & {[0.06,0.10]} & {[0.07,0.10]} & {[0.05,0.08]} & {[0.06,0.10]}\end{array}$ $\begin{array}{lllllllll}(\mathrm{A} 3, \mathrm{~A} 5) & {[0.02,0.03]} & {[0.07,0.10]} & {[0.05,0.08]} & {[0.05,0.08]} & {[0.07,0.10]} & {[0.03,0.05]} & {[0.03,0.05]}\end{array}$ $(\mathrm{A} 4, \mathrm{~A} 5) \quad[0.06,0.11] \quad[0.04,0.09] \quad[0.01,0.07] \quad[0.02,0.07] \quad[0.07,0.13] \quad[0.06,0.12] \quad[0.04,0.09]$ 
Table 13 The interval probability weights under expert D3

\begin{tabular}{|c|c|c|c|c|c|c|c|}
\hline D3 & $\succ$ & $\|$ & $\stackrel{V}{\|}$ & $\underset{\wedge}{\|}$ & $\underset{\wedge}{\stackrel{V}{\|}}$ & $\approx$ & $\prec$ \\
\hline
\end{tabular}

$\begin{array}{llllllll}(\mathrm{A} 1, \mathrm{~A} 2) & {[0.05,0.09]} & {[0.06,0.10]} & {[0.03,0.06]} & {[0.04,0.07]} & {[0.03,0.07]} & {[0.05,0.09]} & {[0.03,0.07]}\end{array}$ $\begin{array}{llllllllll}(\mathrm{A} 1, \mathrm{~A} 3) & {[0.06,0.09]} & {[0.02,0.06]} & {[0.05,0.09]} & {[0.06,0.10]} & {[0.05,0.07]} & {[0,0.05]} & {[0.02,0.06]}\end{array}$ $\begin{array}{lllllllll}(\mathrm{A} 1, \mathrm{~A} 4) & {[0.04,0.07]} & {[0.01,0.04]} & {[0.01,0.03]} & {[0.10,0.14]} & {[0.03,0.06]} & {[0.02,0.04]} & {[0.04,0.07]}\end{array}$ $\begin{array}{llllllllll}(\mathrm{A} 1, \mathrm{~A} 5) & {[0.03,0.06]} & {[0.01,0.05]} & {[0.02,0.05]} & {[0.03,0.06]} & {[0.09,0.14]} & {[0.06,0.10]} & {[0.02,0.05]}\end{array}$ $\begin{array}{llllllllll}(\mathrm{A} 2, \mathrm{~A} 3) & {[0.05,0.08]} & {[0.01,0.04]} & {[0.02,0.05]} & {[0.05,0.08]} & {[0.02,0.05]} & {[0.08,0.12]} & {[0.03,0.05]}\end{array}$ $\begin{array}{lllllllll}(\mathrm{A} 2, \mathrm{~A} 4) & {[0.02,0.07]} & {[0.03,0.05]} & {[0.01,0.05]} & {[0.08,0.11]} & {[0.04,0.08]} & {[0.04,0.08]} & {[0.04,0.08]}\end{array}$ $\begin{array}{llllllllll}(\mathrm{A} 2, \mathrm{~A} 5) & {[0.04,0.08]} & {[0.05,0.09]} & {[0.05,0.09]} & {[0.01,0.05]} & {[0.03,0.07]} & {[0.02,0.05]} & {[0.06,0.11]}\end{array}$ $\begin{array}{llllllllll}(\mathrm{A} 3, \mathrm{~A} 4) & {[0.02,0.08]} & {[0.01,0.08]} & {[0.03,0.09]} & {[0.04,0.10]} & {[0.06,0.12]} & {[0.05,0.12]} & {[0.03,0.09]}\end{array}$ $\begin{array}{llllllllll}(\mathrm{A} 3, \mathrm{~A} 5) & {[0.07,0.11]} & {[0.05,0.10]} & {[0.01,0.07]} & {[0.05,0.10]} & {[0.02,0.07]} & {[0.02,0.07]} & {[0.02,0.07]}\end{array}$ $\begin{array}{llllllll}(\mathrm{A} 4, \mathrm{~A} 5) & {[0,0.05]} & {[0.04,0.08]} & {[0.01,0.05]} & {[0.05,0.09]} & {[0.06,0.10]} & {[0.03,0.08]} & {[0.060 .11]}\end{array}$

Table 14 The interval probability weights under expert D4

\begin{tabular}{|c|c|c|c|c|c|c|c|}
\hline D4 & $\succ$ & $\|$ & $\stackrel{V}{\|}$ & $\stackrel{\wedge}{\wedge}$ & $\begin{array}{l}\vee \\
\| \\
\wedge\end{array}$ & $\approx$ & $\prec$ \\
\hline$(\mathrm{A} 1, \mathrm{~A} 2)$ & {$[0.18,0.24]$} & {$[0.04,0.25]$} & {$[0.09,0.27]$} & {$[0.28,0.37]$} & {$[0.04,0.25]$} & {$[0.24,0.35]$} & {$[0.16,0.29]$} \\
\hline$(\mathrm{A} 1, \mathrm{~A} 3)$ & {$[0.16,0.18]$} & {$[0.26,0.28]$} & {$[0.09,0.13]$} & {$[0.04,0.09]$} & {$[0.15,0.17]$} & {$[0.13,0.17]$} & {$[0.33,0.35]$} \\
\hline (A1, A4) & 0.29 & 0.16 & 0.29 & 0.14 & 0.04 & 0.04 & 0.23 \\
\hline (A1, A5) & {$[0.09,0.26]$} & {$[0.04,0.24]$} & {$[0.24,0.35]$} & {$[0.04,0.24]$} & {$[0.20,0.32]$} & {$[0.24,0.28]$} & {$[0.20,0.32]$} \\
\hline$(\mathrm{A} 2, \mathrm{~A} 3)$ & {$[0.08,0.18]$} & {$[0.04,0.17]$} & {$[0.14,0.22]$} & {$[0.32,0.36]$} & {$[0.18,0.21]$} & {$[0.23,0.28]$} & {$[0.15,0.23]$} \\
\hline (A2, A4) & {$[0.27,0.35]$} & {$[0.15,0.28]$} & {$[0.14,0.27]$} & {$[0.14,0.27]$} & {$[0.04,0.23]$} & {$[0.21,0.32]$} & {$[0.17,0.28]$} \\
\hline (A2, A5) & {$[0.32,0.32]$} & {$[0.09,0.20]$} & {$[0.04,0.13]$} & {$[0.20,0.26]$} & {$[0.08,0.19]$} & {$[0.20,0.27]$} & {$[0.19,0.26]$} \\
\hline (A3, A4) & {$[0.08,0.32]$} & {$[0.08,0.32]$} & {$[0.27,0.40]$} & {$[0.17,0.36]$} & {$[0.23,0.38]$} & {$[0.06,0.32]$} & {$[0,0.31]$} \\
\hline$(\mathrm{A} 3, \mathrm{~A} 5)$ & {$[0.06,0.27]$} & {$[0.06,0.17]$} & {$[0.15,0.31]$} & {$[0.28,0.33]$} & {$[0.13,0.30]$} & {$[0.08,0.28]$} & {$[0.26,0.37]$} \\
\hline$(\mathrm{A} 4, \mathrm{~A} 5)$ & {$[0.10,0.14]$} & {$[0,0.08]$} & {$[0.18,0.20]$} & {$[0.26,0.27]$} & {$[0.17,0.20]$} & {$[0.17,0.19]$} & {$[0.30,0.31]$} \\
\hline
\end{tabular}

Table 15 The interval probability weights under expert D5

\begin{tabular}{|c|c|c|c|c|c|c|c|}
\hline D5 & $\succ$ & $\|$ & $\begin{array}{l}\vee \\
\|\end{array}$ & $\|$ & $\underset{\wedge}{\vee}$ & $\approx$ & $\prec$ \\
\hline$(\mathrm{A} 1, \mathrm{~A} 2)$ & {$[0.10,[0.15]$} & {$[0.08,0.14]$} & {$[0.04,0.06]$} & {$[0.16,0.20]$} & {$[0.22,0.26]$} & {$[0.12,0.17]$} & {$[0.05,0.12]$} \\
\hline (A1, A3) & {$[0.15,0.17]$} & {$[0.06,0.09]$} & {$[0.02,0.12]$} & {$[0.12,0.14]$} & {$[0.25,0.27]$} & {$[0.07,0.10]$} & {$[0.05,0.08]$} \\
\hline (A1, A4) & {$[0.04,0.14]$} & {$[0.09,0.17]$} & {$[0.08,0.16]$} & {$[0,0.13]$} & {$[0.18,0.23]$} & {$[0.14,0.20]$} & {$[0.19,0.25]$} \\
\hline (A1, A5) & {$[0.04,0.06]$} & {$[0.21,0.23]$} & {$[0.04,0.06]$} & {$[0.20,0.21]$} & {$[0.08,0.10]$} & {$[0.06,0.08]$} & {$[0.16,0.17]$} \\
\hline$(\mathrm{A} 2, \mathrm{~A} 3)$ & {$[0,0.10]$} & {$[0.08,0.14]$} & {$[0.16,0.20]$} & {$[0.07,0.13]$} & {$[0.10,0.15]$} & {$[0.12,0.17]$} & {$[0.22,0.26]$} \\
\hline$(\mathrm{A} 2, \mathrm{~A} 4)$ & {$[0.08,0.27]$} & {$[0.09,0.28]$} & {$[0.17,0.31]$} & {$[0,0.14]$} & {$[0.15,0.24]$} & {$[0.04,0.12]$} & {$[0.03,0.24]$} \\
\hline$(\mathrm{A} 2, \mathrm{~A} 5)$ & {$[0.20,0.22]$} & {$[0.15,0.17]$} & {$[0.06,0.08]$} & {$[0.04,0.06]$} & {$[0.22,0.23]$} & {$[0.06,0.08]$} & {$[0.04,0.06]$} \\
\hline (A3, A4) & {$[0.10,0.17]$} & {$[0.04,0.13]$} & {$[0.23,0.27]$} & {$[0.10,0.13]$} & {$[0.11,0.18]$} & {$[0.05,0.13]$} & {$[0.14,0.20]$} \\
\hline (A3, A5) & {$[0.04,0.06]$} & {$[0.12,0.14]$} & {$[0.13,0.14]$} & {$[0.19,0.20]$} & {$[0.16,0.17]$} & {$[0.13,0.15]$} & {$[0.08,0.10]$} \\
\hline (A4, A5) & {$[0.19,0.19]$} & {$[0.04,0.04]$} & {$[0.19,0.20]$} & {$[0.06,0.06]$} & {$[0.05,0.05]$} & {$[0.20,0.21]$} & {$[0.07,0.07]$} \\
\hline
\end{tabular}


Table 16 The group preference probability distribution

\begin{tabular}{|c|c|c|c|c|c|c|c|}
\hline & $\succ$ & $\|$ & $\stackrel{V}{\|}$ & $\stackrel{\|}{\wedge}$ & $\stackrel{\vee}{\|}$ & $\approx$ & $\prec$ \\
\hline$(\mathrm{A} 1, \mathrm{~A} 2)$ & 0.16 & 0.09 & 0.10 & 0.21 & 0.14 & 0.18 & 0.12 \\
\hline$(\mathrm{A} 1, \mathrm{~A} 3)$ & 0.15 & 0.16 & 0.07 & 0.12 & 0.20 & 0.13 & 0.17 \\
\hline$(\mathrm{A} 1, \mathrm{~A} 4)$ & 0.16 & 0.12 & 0.17 & 0.11 & 0.12 & 0.09 & 0.24 \\
\hline (A1, A5) & 0.07 & 0.14 & 0.16 & 0.12 & 0.16 & 0.17 & 0.18 \\
\hline (A2, A3) & 0.08 & 0.11 & 0.15 & 0.18 & 0.13 & 0.18 & 0.17 \\
\hline$(\mathrm{A} 2, \mathrm{~A} 4)$ & 0.16 & 0.12 & 0.18 & 0.14 & 0.10 & 0.15 & 0.15 \\
\hline$(\mathrm{A} 2, \mathrm{~A} 5)$ & 0.24 & 0.13 & 0.08 & 0.13 & 0.15 & 0.13 & 0.13 \\
\hline (A3, A4) & 0.11 & 0.10 & 0.22 & 0.19 & 0.18 & 0.08 & 0.12 \\
\hline (A3, A5) & 0.08 & 0.12 & 0.14 & 0.24 & 0.15 & 0.11 & 0.17 \\
\hline (A4, A5) & 0.14 & 0.05 & 0.17 & 0.15 & 0.14 & 0.18 & 0.17 \\
\hline
\end{tabular}

\section{References}

Abdellaoui M, Bleichrodt H, Paraschiv C (2007) Loss aversion under prospect theory: a parameter-free measurement. Manag Sci 53(10):59-74

Amor SB, Jabeur K, Martel J-M (2007) Multiple criteria aggregation procedure for mixed evaluations. Eur J Oper Res 181(3):1506-1515

Angiz MZ, Tajaddini A, Mustafa A, Kamali MJ (2012) Ranking alternatives in a preferential voting system using fuzzy concepts and data envelopment analysis. Comput Ind Eng 63(4):784-790

Baucells M, Villasís A (2010) Stability of risk preferences and the reflection effect of prospect theory. Theory Decis 68(1):193-211

Bleichrodt H, Schmidt U, Zank H (2009) Additive utility in prospect theory. Manag Sci 55(5):863-73

Cheng M-Y, Tsai H-C, Chuang K-H (2011) Supporting international entry decisions for construction firms using fuzzy preference relations and cumulative prospect theory. Expert Syst Appl 38:15151-15158

Chiclana F, García JMT, Moral MJ, Herrera-viedma E (2013) A statistical comparative study of different similarity measures of consensus in group decision making. Inf Sci 221:110-123

Chuu SJ (2009) Selecting the advanced manufacturing technology using fuzzy multiple attributes group decision making with multiple fuzzy information. Comput Ind Eng 57:1033-1042

Cook WD (2006) Distance-based and ad hoc consensus models in ordinal preference ranking. Eur J Oper Res 172(2):369-385

Fan Z-P, Yue Q, Feng B, Liu Y (2010) An approach to group decision-making with uncertain preference ordinals. Comput Ind Eng 58(1):51-57

Frini A, Guitouni A, Martel J-M (2012) A general decomposition approach for multi-criteria decision trees. Eur J Oper Res 220(2):452-460

González-Pachón J, Romero C (2001) Aggregation of partial ordinal rankings: an interval goal programming method. Comput Oper Res 28:827-834

González-Pachón J, Rodríguez-Galiano MI, Romero C (2003) Transitive approximation to pairwise comparison matrices by using interval goal programming. J Oper Res Soc 54:532-538

González-Pachón J, Romero C (2004) A method for dealing with inconsistencies in pairwise comparisons. Eur J Oper Res 158(2):351-361

González-Pachón J, Romero C (2010) Goal programming: from constrained regression to bounded rationality theories. In: Zopounidis C, Pardalos PM (eds) Handbook of multicriteria analysis. Springer, Heidelberg, pp 311-328

González-Pachón J, Romero C (2011) The design of socially optimal decisions in a consensus scenario. Omega 39(2):179-185

Guo Y et al (2003) Lattice order making. Shanghai Science and Technology Publishing House, Shanghai

Guo Q, Guo C, Guo Y (2010a) Method of group decision-making based on the distance of lattice order preferences. Syst Eng Electron 32(2):298-302 
Guo Q, Guo Y, Guo C (2010b) Alternative ranking based on fuzzy similarity in group decision-making. J Southwest Jiaotong Univ 2:307-311

Guo P, Tanaka H (2010) Decision making with interval probabilities. Eur J Oper Res 203:444-453

Guo C, Guo Q, Guo Y (2012) Random lattice order group decision-making based on interval probability preferences. J Southwest Jiaotong Univ 4:75-82

Guo P, Wang Y (2012) Eliciting dual interval probabilities from interval comparison matrices. Inf Sci 190:17-26

Guo C, Shi R, Guo Q (2011) A method of group decision-making based on preference distance of binary relation. In: 2011 International conference on management science and engineering, ICMSE 2011-18th annual conference proceedings, pp 165-173

He DY (2007) Decision-making under the condition of probability interval by maximum entropy principle. Oper Res Manag Sci 16:74-78

Hüllermeier E, Fürnkranz J, Cheng W, Brinker K (2008) Label ranking by learning pairwise preferences. Artif Intell 172:1897-1916

Hwang CL, Lin MJ (1987) Group decision making under multiple criteria: methods and applications. Springer, Berlin

Jabeur K, Martel J-M, Khélif SB (2004) A distance-based collective preorder integrating the relative importance of the group's members. Group Decis Negotiat 13(4):327-349

Jabeur K, Martel J-M (2007a) A collective choice method based on individual preferences relational systems (prs). Eur J Oper Res 177(3):1549-1565

Jabeur K, Martel J-M (2007b) An ordinal sorting method for group decision-making. Eur J Oper Res 180(3):1272-1289

Jabeur K, Martel J-M (2010) An agreement index with respect to a consensus preorder. Group Decis Negot 19(6):571-590

Jabeur K, Martel J-M, Guitouni A (2012) Deriving a minimum distance-based collective preorder: a binary mathematical programming approach. OR spectr 34(1):23-42

Jullien-Ramasso S, Mauris G, Valet L, Bolon P (2012) A decision support system for animated film selection based on a multi-criteria aggregation of referees' ordinal preferences. Expert Syst Appl 39:4250-4257

Kahneman D, Tversky A (1979) Prospect theory: an analysis of decisions under risk. Econometrica 47: 263-291

Kahraman C, Cevik S, Ates NY, Gulbay M (2007) Fuzzy multi-criteria evaluation of industrial robotic systems. Comput Ind Eng 52(4):414-433

Lee SK, Cho YH, Kim SH (2010) Collaborative filtering with ordinal scale-based implicit ratings for mobile music recommendations. Inf Sci 180(11):2142-2155

Liu Y, Fan Z-P, Zhang Y (2014) Risk decision analysis in emergency response: a method based on cumulative prospect theory. Comput Oper Res 42(2):75-82

Lodwick WA, Jamison KD (2008) Interval-valued probability in the analysis of problems containing a mixture of possibilistic, probabilistic, and interval uncertainty. Fuzzy Sets Syst 159:2845-2858

Ma J, Fan Z-P, Jiang Y-P, Mao J-Y, Ma L (2006) A method for repairing the inconsistency of fuzzy preference relations. Fuzzy Sets Syst 157(1):20-33

Ma L-C (2010) Visualizing preferences on spheres for group decisions based on multiplicative preference relations. Eur J Oper Res 203:176-184

Meng D, Pei Z (2013) On weighted unbalanced linguistic aggregation operators in group decision making. Inf Sci 223:31-41

Podinovski VV (2010) Set choice problems with incomplete information about the preferences of the decision maker. Eur J Oper Res 207(1):371-379

Podinovski VV (2012) Sensitivity analysis for choice problems with partial preference relations. Eur J Oper Res 221(1):198-204

Rebai A, Aouni B, Martel J-M (2006) A multi-attribute method for choosing among potential alternatives with ordinal evaluation. Eur J Oper Res 174(1):360-373

Richard G, Wu G (1999) On the shape of the probability weighting function. Cogn Psychol 38:129-166

Roy B, Slowinski R (1993) Criterion of distance between technical programming and socio-economic priority. RAIRO Rech Opér 27:45-60

Saaty TL (1990) How to make a decision: the analytic hierarchy process. Eur J Oper Res 48(1):9-26

Schmidt U, Zank H (2008) Risk aversion in cumulative prospect theory. Manag Sci 54(1):208-16

Tavares LV (2012) An acyclic outranking model to support group decision making within organizations. Omega 40(6):782-790 
Tversky A, Kahneman D (1992) Advances in prospect theory: cumulative representation of uncertainty. J Risk Uncertain 5:297-323

Wang YM, Yang JB, Xu DL (2005) A preference aggregation method through the estimation of utility intervals. Comput Oper Res 32(8):2027-2049

Weichselberger K, Pohlmann S (1990) A methodology for uncertainty in knowledge-based systems. Lecture notes in artificial intelligence. Springer, Berlin

Xia M, Xu Z (2012) Entropy/cross entropy-based group decision making under intuitionistic fuzzy environment. Inf Fusion 13:31-47

Yager RR, Kreinovich V (1999) Decision making under interval probabilities. Int J Approx Reason 22: 195-215

Yager RR (2011) On the fusion of imprecise uncertainty measures using belief structures. Inf Sci 181: 3199-3209 